\title{
A CERÂMICA PAULISTA: CINCO SÉCULOS DE PERSISTÊNCIA DE PRÁTICAS TUPINIQUIM EM SÃO PAULO E PARANÁ, BRASIL
}

\author{
Francisco Silva Noelli ${ }^{1}$ \\ Marianne Sallum ${ }^{2}$ \\ ${ }^{1}$ Universidade de Lisboa, Lisboa, Portugal \\ ${ }^{2}$ Museu de Arqueologia e Etnologia, Universidade de São Paulo, \\ São Paulo/SP, Brasil
}

\begin{abstract}
"An element of domestic life, and a chief item of household furniture, Brazilian crockery-ware is interesting to a stranger."

Thomas Ewbank (1856:357)
\end{abstract}

A epígrafe resume os relatos de viajantes que descreveram a parte de dentro das residências rurais no Brasil nos séculos XIX e XX. As vasilhas cerâmicas produzidas localmente (sem vidrado na superfície) foram os principais itens domésticos da maioria dos lares até a primeira metade do século XX, quando passaram a ser substituídas por recipientes industrializados. Tal fato não foi concomitante no país, variando quanto ao local e à região, restando atualmente poucos lugares que produzem cerâmica para o uso residencial e comercial. Todavia, tais vasilhas constituem tema de investigação sobre aspectos tecnológicos, econômicos e sociais da materialidade brasileira. A maioria dessas cerâmicas e seus contextos de produção e uso permanecem pouco ou nada pesquisados.

Em alguns lugares do estado de São Paulo ainda são produzidas cerâmicas domésticas. Dentre elas, existe a "cerâmica popular do estado de São Paulo", definida na pesquisa etnográfica de Herta Löell Scheuer, nos anos 1960. Ela registrou a prática cerâmica em nove áreas de São Paulo e uma do Paraná (Scheuer 1982:21-23) como "produtos de cerâmica utilitária... aproveitados para inúmeras possibilidades... onde nota-se a existência de influxos da cultura indígena", considerando que as "manufaturadas no sul mostram parentesco estilístico". Ela também verificou que os cânones dessa prática das mulheres eram transmitidos de uma geração à outra, cujas memórias remontavam à metade do século XIX, podendo-se "constatar uma 
continuidade nas formas...", "onde todos os recipientes são manufaturados em estilo uniforme" e com "tenaz apego às formas tradicionais... o que se pode atribuir a uma motivação espiritual. Conscientes da tradição, permanecem fiéis a ela, transmitindo o saber da mesma maneira" (Scheuer 1976:6). A pesquisa arqueológica em Peruíbe mostrou que essa cerâmica já era produzida no final do século XVII (Sallum 2018), revelando a persistência de práticas por mais de 300 anos no litoral ao sul de São Vicente, abrindo caminho para reconhecer que a sua produção começou muito tempo antes.

\section{Objetivo e fontes de pesquisa}

A partir da perspectiva da arqueologia da persistência, apresentaremos os resultados da nossa investigação sobre a notável itinerância das práticas de mulheres ceramistas. Para identificar os seus processos de produção e uso, analisamos diversas fontes para criar uma base de dados interdisciplinar. Em termos tecnológicos, verificamos a presença de atributos indígenas e da cerâmica comum portuguesa em Scheuer e nas coleções de vasilhas do sudeste de São Paulo e nordeste do Paraná. Em termos sociais e históricos, constatamos a evidente presença Tupiniquim na construção da sociedade colonial de São Paulo. Assim, existe fundamentação para definir mais especificamente a cerâmica objeto deste artigo, avançando em relação aos conceitos de cerâmica "neobrasileira" e "local/regional" (Zanettini 2005), conceitos que visaram classificar provisoriamente as materialidades coloniais ainda não investigadas em seus processos de apropriação e transformação.

Para compor nossa base inicial de dados:

1. analisamos 3 mil fragmentos e vasilhas semi-inteiras do sítio arqueológico Ruínas do Abarebebê, no Museu Histórico e Arqueológico de Peruíbe e no Museu de Arqueologia e Etnologia da Universidade de São Paulo;

2. visitamos 37 museus (São Paulo, Paraná, Rio de Janeiro e Mato Grosso do Sul) e analisamos 230 vasilhas (187 tupiniquim, 54 "cerâmica popular de São Paulo");

3. iniciamos trabalho de campo etnográfico com ceramistas nas cidades onde Scheuer pesquisou, em busca de dados tecnológicos e memórias;

4. realizamos leituras de fontes escritas publicadas e inéditas, quase todas sobre São Paulo (séculos XVI, XVII e XVIII); 
5. começamos um banco de dados sobre a linguagem da cerâmica e dos seus usos, com registros de São Paulo e Paraná (Scheuer 1967, 1976, 1982; Nascimento 1986) e Portugal (Fernandes 2012; Bugalhão \& Coelho 2017).

Com os resultados obtidos e a confirmação das conclusões destacadas acima sobre o "parentesco estilístico", bem como a manutenção das formas ao longo do tempo, revisamos os fundamentos da definição da "cerâmica popular de São Paulo". Scheuer seguiu um critério binário derivado da noção de assimetria social, "popular" em oposição a "culto", cunhado pelos etnógrafos portugueses do século XIX e pelos folcloristas brasileiros, que consideravam "arte popular" a materialidade produzida localmente em contextos familiares autossustentados, contrapondo-a às "artes elevadas" e aos artigos industrializados. Considerando o processo histórico regional, sugerimos a substituição do conceito de Scheuer pelo conceito "cerâmica paulista", que definimos como a "cerâmica comum portuguesa apropriada e transformada no século XVI pelas Tupiniquim da área de São Vicente, para uso nos assentamentos coloniais, reproduzida até o presente na região Sudeste de São Paulo" (Figura 1). Ela foi a primeira cerâmica colonial de São Paulo, produzida em território, contexto histórico e social específicos na perspectiva tupiniquim, fora da lógica econômica europeia, para uso doméstico ou trocas no circuito familiar. E essa cerâmica foi levada para além de São Paulo, acompanhando a fundação de núcleos paulistas em diversos locais do Brasil, mas ainda não houve a oportunidade de realizar comparações com as vasilhas arqueológicas e históricas encontradas em tais lugares. A mercantilização da cerâmica paulista é um tema aberto, mas parece estar mais relacionada ao surgimento das redes regionais de abastecimento da urbanização no século XVIII e ao interesse comercial do mercado dos artesanatos da segunda metade do século XX. 
Figura 1: Área de distribuição inicial da cerâmica paulista

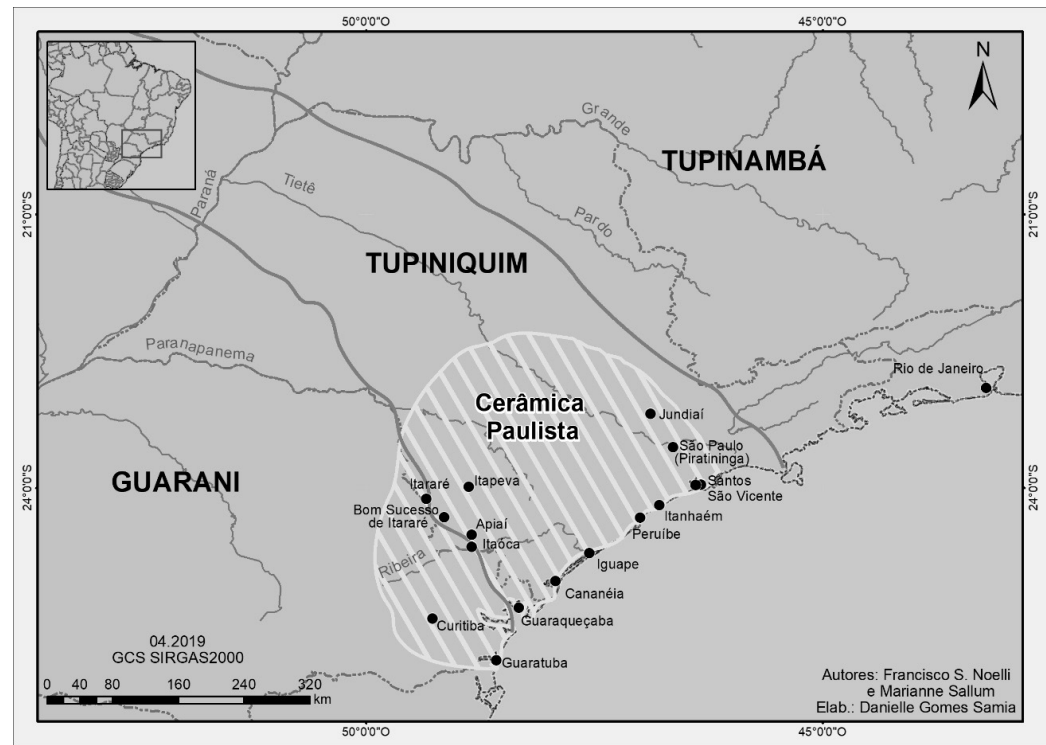

\section{Arqueologia do colonialismo}

A cerâmica paulista começou a ser produzida no contexto do colonialismo na Capitania de São Vicente, no século XVI. Os portugueses se estabeleceram ali graças à aliança política com uma parte da população tupiniquim, potencializando interesses estratégicos de ambos para escravizar outros povos, mas também desenvolvendo sociabilidades e parentesco. De um lado, os indígenas aceitaram aliados para suas guerras com os diversos povos não Tupiniquim. De outro, os portugueses perceberam um meio para se estabelecer e viram na guerra para capturar escravos a oportunidade para ingressar no sistema comercial Atlântico. A aliança durou duzentos anos com estas características até o começo do século XVIII, um longo período marcado por mudanças demográficas, sociais, econômicas e políticas que reconfiguraram gradativamente a organização da sociedade colonial: 1. os Tupiniquim passaram de maioria a minoria; 2 os descendentes das tupiniquim com os portugueses tornaram-se maioria; 3. os portugueses e demais europeus sempre foram minoria até o século XVIII. 
Nosso artigo reflete sobre a persistência, iniciada com a apropriação e transformação da cerâmica portuguesa no século XVI e a sua itinerância até hoje. Muitos trabalhos contemporâneos têm buscado não apenas reconstruir uma história colonial centrada em registros de declínio demográfico, vitimização e perda cultural das populações ameríndias, mas também na sua condição de protagonistas dinâmicos em luta constante por autonomia, o que marcou processos históricos de longo prazo até o presente. Tal mudança de perspectiva tem demandado revisões descolonizadoras da história, mais éticas e menos eurocêntricas.

As narrativas tradicionais de contato, conquista e colonização, baseadas em noções de perda, assumiram que o período pré-colonial foi o último momento de autenticidade indígena (Law Pezzarossi \& Sheptak 2019). Tais noções ainda brilham no firmamento da arqueologia do século XXI, tornando-se deletérias em estudos coloniais e pós-coloniais. Na América Latina, fundam análises pautadas em dualidade maniqueísta, esvaziando a complexidade das relações entre indígenas e europeus, convertendo os primeiros em meras vítimas (Feros 2017). É necessário romper com tais paradigmas anacrônicos e compreender como as pessoas agiam nos processos coloniais, não apenas como coprodução relacional da ordem colonial (Sheptak et al. 2010), mas também percebendo o papel das trocas e das alianças entre europeus e indígenas (Viveiros de Castro 2004).

Entendemos a apropriação tupiniquim como "manifestações legítimas de modos específicos de se produzir e utilizar substâncias, matérias-primas e objetos segundo lógicas de classificação e transformação específicas" (Lagrou 2013:22). Tratamos também da transformação da cerâmica comum portuguesa na cerâmica paulista e da sua reprodução por quase 500 anos. Procuramos uma compreensão descolonizada da aliança indígena e europeia no litoral sul de São Paulo, cujas práticas demonstraram autonomia e a agência tupiniquim. A transformação da cerâmica pertence ao "paradigma da troca", no qual "o evento de troca é sempre a transformação de um evento de troca anterior. Não há um começo absoluto, sem um ato de troca absolutamente inicial. Cada ato é uma resposta, isto é, uma transformação de uma lembrança anterior do mesmo tipo" (Viveiros de Castro 2004:477).

A prática cerâmica colonial tupiniquim persistiu até o presente como um habitus. Contudo, ainda é difícil rastrear nas fontes escritas a identidade tupiniquim a partir do século XVIII, sendo um problema para resolver, apesar de indícios da sua permanência no sudeste de São Paulo, como veremos abaixo. Não consideramos que a persistência da prática cerâmica sem pessoas identificadas como tupiniquim seja um paradoxo ou uma impossibilidade, mas sim o legado de conhecimentos transmitidos entre as gerações nas 
comunidades de práticas. A definição da identidade de quem produziu essa cerâmica na longa duração é complexa, exigindo muita pesquisa histórica para encontrar as pessoas na documentação colonial, ao lado da pesquisa etnográfica para conhecer a memória e as concepções atuais.

A contraprova aos registros escritos para superar o vazio epistemológico sobre a identidade indígena nos assentamentos rurais e na periferia dos núcleos urbanos deveria vir do contexto arqueológico, possivelmente a evidência mais eloquente da vida cotidiana no passado. E junto com o registro arqueológico, os dados demográficos dos nascimentos, casamentos e óbitos das paróquias, mais os inventários, testamentos e registros de imóveis. Trata-se de alternativas para superar o laconismo da burocracia, especialmente do século XVIII, pautada por uma lei da Era Pombalina que diluiu a diversidade das identidades indígenas e fez surgir o "índio genérico" como estratégia da Coroa para "misturar a população colonial" (Morales \& Moi 2008), uma política vigente até o século XX.

Buscamos alternativas analíticas não binárias de colonialismo e comunidades indígenas (Dawdy 2005; Hayes \& Cipolla 2015), contrapondo termos que reforçam a visão unilateral e colonizadora da história. O colonialismo não é apenas uma fase cronológica, mas sim modalidade de poder cujos impactos são multidirecionais, espraiando-se na longa duração (Cohn 1986), exigindo revisões das noções de mudança cultural e agência nos contextos coloniais (Silliman 2001).

A materialidade, a cadeia operatória e os seus usos são centrais para o entendimento da relacionalidade dos processos coloniais (Gosden 2004; Voss 2008). Elas conotam minúcias e complexidades inexistentes em outras categorias de fontes, como as escritas (Cooper 2005), possibilitando compreender as respostas das populações nativas às políticas coloniais. Se a colonização alterou "mundos não questionados" (Silliman 2001:196), as respostas seguiram lógicas culturais particulares e locais (Lightfoot 2005; Schmidt \& Mrozowski 2013). Diante do impacto do colonialismo, as práticas indígenas demonstram, muitas vezes, processos de continuidade insuspeitáveis (Rubertone 2000), e persistências (Silliman 2009; Panich 2013). Compreendê-los permite desestabilizar as narrativas oficiais sobre o colonialismo (Funari \& Senatore 2015), problematizar categorias analíticas como hibridismo (Silliman 2015) e (não) mestiçagem (Goldman 2017), sublinhar a historicidade da agência (Johnson 2006) e a ação social de coletivos específicos (Ferreira \& Funari 2015).

Tal mudança de paradigma demanda a descolonização das abordagens arqueológicas, antropológicas e históricas (Rizvi 2008; Battle-Baptiste 2011), inspirada pela reflexão e a ação crítica de indígenas e não indígenas dedicados ao engajamento social e à valoração das comunidades locais na construção do 
conhecimento (Atalay 2008; Cipolla et al. 2018). Nas últimas duas décadas, no Brasil, a história colonial e o passado recente dos coletivos indígenas e das comunidades tradicionais vêm sendo repensados. Não obstante, ainda são escassos os debates sobre tais temas na arqueologia (Amaral 2012; Symanski \& Gomes 2012; Silva 2013; Moura \& Allen 2015; Silva \& Noelli 2015; Muniz \& Gomes 2017; Souza \& Lima 2017; Sallum 2018). A maioria se dedica aos contextos da escravização de africanos e afro-brasileiros (Lima 2002; Agostini 2010; Symanski 2010; Souza 2013; Ferreira 2015; Hartemann \& Moraes 2018).

O desinteresse pela história indígena de longa duração teve como lastro a divisão artificial entre pré-história e história, desafiando a compreensão de interpretações antropológicas (Lightfoot 1995). Recentemente, Souza (2017) salientou que, no Brasil, os(as) arqueólogos(as) valoram identidade apenas de indígenas pré-coloniais, quando eles estariam livres da influência europeia, antes de começarem a "degenerar", como pensava parte dos pesquisadores (Noelli \& Ferreira 2007). O foco exclusivo na perda cultural simplifica e reduz o entendimento da construção das identidades. Recoloniza o passado de várias maneiras, silenciando a inventividade, o protagonismo e a persistência em face do colonialismo. A recolonização inclui a visão de que os indígenas, ao transformarem suas práticas sociais, seriam menos interessantes ou menos "puros" se comparados com os povos pré-coloniais (Silliman 2012). Tal noção realça os efeitos nefastos do colonialismo e dá aval à perspectiva redutora da dominação cultural (Howard 2002).

\section{Persistência de práticas culturais em São Paulo}

Persistência não é sinônimo de continuidade histórica, mas a articulação "intencional de certas práticas e identidades relativas à luz de novas economias, políticas e realidades sociais [...] unindo efetivamente passado e presente numa dinâmica e inquebrável trajetória" (Panich et al. 2018:11-12). Tal situação levou a uma aliança profunda e não rompida até o final do século XVII, quando os descendentes de tupiniquim e portugueses eram maioria na Capitania de São Vicente, sua sociedade sendo conhecida posteriormente como "bandeirante". Em parte, combatiam e escravizavam povos indígenas "inimigos" para transformá-los em mercadoria para integrar-se à economia do sistema atlântico (Monteiro 1994).

Para os povos Tupi, uma parte da sua identidade está no "outro" escolhido para incorporar. É na afinidade que se encontra a dimensão cosmológica e política, na qual o "outro" é primeiro e, acima de tudo, um afim. Poderiam ser amigos, aliados, hóspedes, parceiros comerciais, estrangeiros 
e inimigos e, também, animais e espíritos, todos envolvidos nos valores da afinidade. O parentesco é construído com base relacional, que se manifesta como um processo constantemente atualizado (Viveiros de Castro 2001). Entre os Ameríndios, conforme Lagrou (2013:22), “as coisas e as pessoas podem ser transformadas, domesticadas, pacificadas e incorporadas sem perderem sua relação com a externalidade". Assim podemos dizer que a afinidade na concepção tupiniquim os aproximou dos portugueses, sendo os descendentes das relações entre eles considerados tupiniquim. Mas como quem escreveu as fontes históricas foram os portugueses e outros europeus, registraram na maioria das vezes os descendentes como "portugueses", "católicos", "mamelucos" ou "mestiços".

A partir do século XVIII, a minoria dos descendentes dominava a economia e a gestão da Colônia associados aos novos portugueses imigrantes ligados à nobreza e à burocracia, enquanto a maioria dos descendentes e dos indígenas escravizados deixaram de ser tratados por seus etnônimos na documentação colonial. Esse século também inaugurou, em São Paulo, o ingresso numericamente significativo de escravos africanos e afrobrasileiros, iniciando um novo processo social local, incluindo contribuições à materialidade e à linguagem. A Era Pombalina (1750-1777) foi marcada pela crescente desigualdade entre os súditos coloniais e pela hegemonia política da Coroa em São Paulo, o que não ocorrera antes quando os Tupiniquim eram maioria demográfica. O impacto das leis pombalinas, sobretudo a inclusão do tratamento como "índio" na papelada burocrática, e a proibição do uso das línguas indígenas contribuíram para: 1. mudanças que influenciaram uma espécie de apagamento gradativo das identidades e das heranças culturais indígenas; 2. o reforço de preconceitos raciais e de classe. Apesar disso, em meados do século XIX, a língua geral paulista ainda era falada em alguns lugares, incluindo a área de Iguape, no litoral sul (Leite 2013:22-23).

A transmissão de conhecimentos foi o vetor da persistência e o maior legado dos Tupiniquim às gerações seguintes, criando elos entre passado e presente. Ela começou com a coprodução intencional de práticas entre os Tupiniquim e os portugueses, baseada nas políticas de colaboração e reciprocidade, favorecendo relações e um ambiente peculiar de sociabilidade, a ponto de o primeiro donatário da Capitania de São Vicente, Martim Afonso de Sousa, declarar em 1533 a Francisco Carneiro, secretário do rei D. João III: "sob o Trópico de Capricórnio, no vigésimo terceiro grau além da referida linha, chegou onde encontra uma terra igualmente bemaventurada" (Radulet 1991:99). O relato de 1532, feito por Pero Lopes, irmão de Martim Afonso, descreve a fundação oficial de São Vicente e revela a estratégia para a eficiência do processo colonial, destacando a importância 
de os portugueses "viverem em comunicação das artes" com os indígenas (Sousa 1994:184), referindo-se, pois, à "troca de práticas", à compreensão do modo de viver tupiniquim.

A apropriação da cerâmica foi baseada na competência tecnológica indígena pré-colonial e na articulação de práticas com portugueses para produzir a cerâmica paulista nas primeiras décadas da Colônia. A princípio, a produção de cerâmica na Capitania de São Vicente foi tupiniquim para ser usada nos assentamentos; a continuidade da produção foi realizada por suas descendentes e pessoas de distintas procedências que se fixaram no sudeste de São Paulo e nordeste do Paraná e incorporaram tais práticas, acompanhando a expansão colonial até o século XVIII.

Na Capitania de São Vicente a articulação de práticas não significou predomínio, equivalência ou desequilíbrio, como veremos adiante. A definição da materialidade colonial não deu predomínio a um lado ou a outro. No caso da apropriação da cerâmica portuguesa, parece que foi uma maneira de as Tupiniquim exercerem a sua alteridade para, simultaneamente, potencializarem suas diferenças. E não equivaleu a hibridismo, uma conceituação dependente do contexto social, envolvendo sutilezas não inerentes aos objetos. O hibridismo depende da prática, não sendo ponto de chegada ou resultado; não é uma solução definitiva, mas processo em permanente transformação (Loren 2013; Liebmann 2015; Silliman 2015).

No caso tupiniquim em São Paulo, a mudança da cerâmica não ocorreu em um ambiente de resistência colonial. Uma interpretação possível seria considerar a apropriação e a noção antropológica da predação como exercícios da alteridade tupi (Ribeiro \& Jácome 2014), da incorporação do outro que foi escolhido por afinidades como meio de uma construção social constantemente atualizada (Viveiros de Castro 1992). Para os Tupi, a identidade não seria estabelecida pela essência individual ou coletiva dada a priori, ao contrário, é durante o processo que a transformação do outro se institui como essência da sua cosmologia (Perrone-Moisés 2014). É possível considerar que as mudanças experimentadas pelos Tupiniquim que se aliaram aos portugueses fossem compatíveis com a lógica das suas alteridade e cosmologia, talvez em função do desejo e da decisão de se relacionarem socialmente com os recém-chegados e se apropriarem de suas tecnologias. Mas isso não significou perda cultural, e sim persistência cultural.

Estamos no mesmo caminho das pesquisas antropológicas no Brasil, procurando entender "a complexidade dos modos indígenas de construção da história" (Albert 2002:10), em três perspectivas interligadas: 1. histórica (processo colonial); 2. política (táticas de reprodução social); 3. simbólica 
(conceitos de alteridade). Busca-se aproximar da cosmologia indígena para entender processos de mudança e continuidade, identificando as dialéticas específicas de identidade e alteridade (Fausto \& Heckenberger 2007).

Tais temas são duplamente programáticos: ao mesmo tempo em que são dispositivos de representação, procuram domesticar simbólica e ritualmente a alteridade dos não indígenas (Albert 2002). Pacificar os brancos é noção polissêmica. Requer vincular o colonizador branco e os objetos que lhe pertencem às cosmologias nativas; implica esvaziar o colonizador de sua letalidade e crueldade, de sua agressividade bélica e material, para sublinhar suas fragilidades e, ao mesmo tempo, vislumbrar novas relações. O ponto de vista nativo, ontologicamente fundamentado, humaniza os colonizadores. Assim, pretende-se e pode-se reproduzir sua própria sociedade, não mais contra o colonizador, mas através dele, que é atraído para a alteridade indígena (Carneiro da Cunha 2002). É preciso enfatizar radicalmente as ontologias nativas para não reduzir os debates à esterilidade dos conceitos de autenticidade e inautenticidade (Fausto \& Heckenberger 2007), nem decidir o que é ou não indígena, ou quaisquer tipos de fronteiras para indicar identidade, pois limitariam a compreensão da persistência nativa (Law Pezzarossi \& Sheptak 2019).

É necessário instituir uma linha de pesquisa sobre a arqueologia da persistência colonial paulista, cujos efeitos ainda são sentidos na atualidade. Com a prática cerâmica, começamos pela revisão da complexidade das relações entre portugueses e Tupiniquim, na qual consideramos a agência das mulheres e seus saberes transmitidos por gerações. As Tupiniquim tiveram como referência as cerâmicas comuns portuguesas com pastas vermelhas, castanhas e laranjas, claras ou escuras, sem a superfície vidrada (Newstead \& Casimiro 2015). Os nossos registros sugerem que a cerâmica preta produzida na metade norte de Portugal (Fernandes 2012) teria servido como modelo por causa do uso de corantes negros vegetais usados para cobrir as vasilhas, prática pré-colonial inexistente entre as Tupiniquim.

\section{Os Tupiniquim}

Eles também foram chamados de Tupi pelos jesuítas, falavam um dialeto tupinambá ou uma língua muito próxima dele (Rodrigues \& Cabral 2002). Por estar precariamente documentado, há dificuldades para uma classificação precisa, mas pertencia à família Tupi-Guarani, filiada ao tronco linguístico tupi, compartilhando práticas e materialidades com mais 70 povos (Rodrigues \& Cabral 2012). 
A convergência de dados históricos sobre a formação dos núcleos compartilhados com os portugueses permite a hipótese de que a cerâmica paulista foi inicialmente produzida no litoral sul de São Paulo, ao redor de São Vicente. No início do século XVI, os Tupiniquim somavam milhares de pessoas em inúmeras aldeias, desde a costa atlântica até o rio Paraná, por cerca de $1 \mathrm{mil} \mathrm{km}$ na bacia do rio Tietê (Corrêa 2014). A Figura 1 mostra a área aproximada dos seus domínios, onde já foram registrados quase 1.400 sítios arqueológicos nos estados de São Paulo, Paraná e Mato Grosso do Sul. Como a maioria dos Tupi, os Tupiniquim manejavam a floresta, cercados por roças onde praticavam a policultura agroflorestal, alimentando-se com inúmeros itens da flora e da fauna, processando-os em vasilhas com funções específicas e adequadas para preparar e servir a sua dieta (Brochado 1991; Noelli \& Brochado 1998).

A cerâmica tupiniquim pré-colonial teve longa duração, por aproximadamente 15 séculos (Corrêa 2014). Ela tinha, paradoxalmente, uma padronização marcada por elevada variabilidade morfológica e de combinações de tratamentos de superfície. A variabilidade resultava da criatividade individual, tal como entre as Guarani, que "concebiam as vasilhas como um empilhamento de zonas ou segmentos horizontais bem demarcados", definidas como as "unidades padrão, de formas definidas que, sobrepostas, darão o contorno da vasilha" (La Salvia \& Brochado 1989:116), ou seja, a variabilidade se explica por fatores intrínsecos dos Tupiniquim e não por causas externas. A variabilidade resultava de inúmeras combinações de um vasto repertório de segmentos de perfil da vasilha ensinados sistematicamente para cada nova geração de ceramistas. E assim podemos concluir que a padronização era a própria variabilidade, a tal ponto que a diferença era a norma que tornava as morfologias tão semelhantes por tanto tempo. 
Figura 2: Transporte da cerâmica paulista no vale do Ribeira-Iguape, c. 1970.

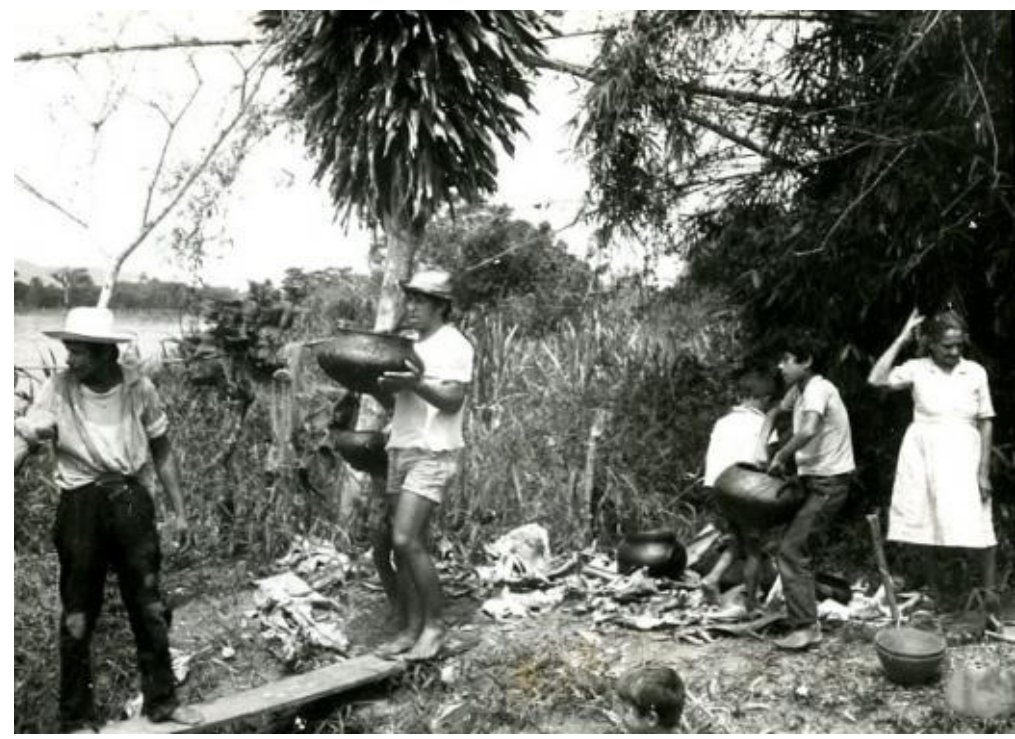

Foto: R. Stulbach, acervo MIS-São Paulo

\section{Agência das mulheres tupiniquim}

A relação entre os Tupiniquim e os portugueses trouxe novidades para ambos em diversos campos do conhecimento, das práticas e da política. A materialidade e a culinária oferecem uma pauta imensa para demonstrar variados aspectos dessas relações, que deveriam ser investigados por uma agenda interdisciplinar. No caso da cerâmica, os dados sugerem que a cerâmica paulista surgiu de conhecimentos tecnológicos milenares que permitiram às mulheres tupiniquim apropriarem-se das cerâmicas portuguesas. Seu sistema educacional, similar à noção teórica de comunidades de práticas (Wendrich 2012), legou aos descendentes e às pessoas que vieram de fora conhecimentos reproduzidos até hoje, sublinhando uma trajetória de persistência capaz de articular diferenças culturais e estabelecer duradouras composições coletivas desde o período colonial. No caso da culinária, a comida indígena foi transformada com a adoção de novos ingredientes. A incorporação de novos alimentos trazidos pelos europeus e, posteriormente, pelos africanos foi legada à tradição culinária caipira (Dória \& Bastos 2018). 
Os portugueses formavam um grupo heterogêneo, divididos pela desigualdade social e apenas parte deles integrou-se ao sistema tupiniquim e apoiou as lutas contra os Carijó, os Tupinambá e as populações Jê; e formou famílias conforme a organização social dos seus aliados indígenas, abrindo mão das suas regras europeias de divisão social por gênero e do arranjo familiar monogâmico nos primeiros dois séculos. Do mesmo modo, as Tupiniquim adotaram hábitos de consumo e incorporaram parte da tecnologia e das práticas portuguesas. A desigualdade entre os portugueses não fazia sentido entre os Tupiniquim, sociedade na qual a pessoa valia pela contínua afirmação dos seus conhecimentos, méritos e feitos pessoais. É provável que a maioria saiu da desigualdade encontrando espaço de convivência social, econômica e política que as normas do Reino não lhes proporcionava. Ao mesmo tempo, protegida entre os indígenas, essa maioria isolou nos dois primeiros séculos a minoria composta por nobres, burocratas e clérigos, configurando o "autonomismo paulista" (Alencastro 2000:139). A virada ontológica para descolonizar e revisar o contexto sociopolítico e cultural na Capitania de São Vicente é a nossa hipótese, começando por inverter a versão acadêmica dominante. Assim, dentre outros problemas, pressupõe desenvolver investigações rompendo dicotomias entre epistemologia e ontologia, colonizadores e colonizados, descontruindo a homogeneidade dos blocos Tupiniquim e português e, também, fazendo aflorar o ponto de vista indígena na análise dos contextos coloniais.

Ao resumir os primeiros 82 anos da colônia, o missionário José de Anchieta (1988:314, 441) escreveu, em 1584, que os Tupiniquim estavam entre os indígenas "mais políticos" e que nunca houve na Capitania de São Vicente "guerras com os índios naturais que chamam Tupis [Tupiniquim], que sempre foram amigos dos portugueses, salvo no ano de 1562, que uns poucos do sertão por sua maldade (ficando a maior parte amiga como dantes) deram guerra a Piratininga, vila de São Paulo".

A leitura das fontes coloniais mostra que havia uma fluidez nas relações entre homens e mulheres tupiniquim que garantia a estabilidade social com uma política de colaboração entre gêneros, prática assumida pelos portugueses que se integraram. As mulheres eram a principal conexão cotidiana com os europeus, dividindo com os homens a gestão dos assentamentos e diversos aspectos da transmissão de conhecimentos, sendo as responsáveis pelo manejo dos estoques alimentares vegetais, a base da sua dieta. Eram responsáveis pela produção de diversos objetos, incluindo os relativos à alimentação, e por diversas outras atividades práticas e simbólicas necessárias para cumprir o calendário anual da segurança alimentar. Elas foram cruciais no sistema colonial, mediando relações nos núcleos familiares e com os europeus, papel fundamental ignorado na narrativa tradicional. 
A produção local da cerâmica era um indicador da autodeterminação e autonomia residencial tupiniquim e, depois, uma alternativa para a maioria dos colonos não depender do comércio atlântico. No século XIX, ou talvez antes, a prática cerâmica passou a complementar o sustento doméstico; sua comercialização local e regional serviu para adquirir bens e itens na economia de trocas. A produção local de cerâmica e a de alimentos nas roças eram práticas que afirmavam a autodeterminação e reduziam a necessidade de vender a força do trabalho, reproduzindo uma parcela da estrutura econômica tupiniquim e de suas transformações coloniais. A pesquisa etnográfica de Scheuer $(1967,1976)$ é um testemunho da independência e da agência das ceramistas, cujas vidas foram estereotipadas como metonímia de pobreza e perda cultural nos relatos de viajantes, religiosos, naturalistas e burocratas. O despojamento das residências e das aparências foi descrito como miséria e indolência, como fez Saint-Hilaire (1995:179), quando viu no caminho para Guaratuba, em 1820, "um mísero casebre feito de varas fincadas umas ao lado de outras e que davam passagem ao vento e à chuva. Algumas panelas e esteiras eram tudo que havia na casa, e seus moradores estavam cobertos de andrajos". Ele e os demais pareciam ignorar deliberadamente que tais pessoas tinham uma vida autossustentada e que dependiam inteiramente de si próprias, dos seus conhecimentos tradicionais e das suas redes locais de colaboração.

\section{O aldeamento de São João Batista}

O sítio arqueológico Ruínas do Abarebebê (CNSA SP00337) foi o aldeamento colonial indígena de São João Batista, atual Peruíbe, litoral sul de São Paulo (Petrone 1995; Cali 1999). Seu contexto e estratigrafia servem como modelo da sequência de ocupação dos assentamentos tupiniquim que possuem registros coloniais. As fontes confirmam a continuidade de Peruíbe desde a primeira metade do século XVI até agora.

Os registros mostram que foi território tupiniquim até a chegada dos portugueses. Embora a carta de doação de terras de 1553 declare que ali houve uma aldeia indígena (Leite 1938:541-542), este local ainda não foi arqueologicamente delimitado, estando provavelmente sob a área mais antiga da cidade, próximo da foz do rio Preto. Em 1605, havia ali um núcleo rural (Rodrigues 1940:199) povoado pelos Tupiniquim, portugueses, seus descendentes e, escravos indígenas de procedência indefinida, como era comum na região. Houve ali contínua presença humana, até a fundação do vizinho aldeamento religioso de São João Batista na segunda metade do século XVII, estabelecido a 8,5 km do rio Preto. 
A pesquisa arqueológica revelou um ponto intermediário da cronologia da cerâmica paulista no litoral sul de São Paulo, fixado entre o final do século XVII e a primeira metade do XVIII (Sallum 2018). Na metade do século XIX temos o registro etnográfico da memória de práticas e da genealogia de linhagens de ceramistas (Scheuer 1976; Nascimento 1986). Entre essas mulheres, encontramos relatos sobre a transmissão de conhecimentos entre as gerações, dedicada a reproduzir e a manter um "estilo uniforme" (Scheuer 1976:56). A comparação dos dados locais com os regionais nos possibilitou compreender o processo que levou à transformação da cerâmica portuguesa pelas mulheres tupiniquim, provavelmente ocorrido entre 1502 e 1550. Seria, também, uma estratégia que permitiria aos portugueses suprirem com artefatos locais a sua materialidade europeia, superando a vinda intermitente e rara de barcos de Portugal, podendo se beneficiar dos alimentos que trouxeram para São Vicente e manter parte das práticas culinárias portuguesas.

São João Batista é um estudo de caso que poderá revelar a identidade dos seus habitantes e sugerir um método para superar o apagamento imposto pela burocracia pombalina. Foi um aldeamento indígena garantido por 212 anos pela Coroa e administrado por franciscanos (1692-1804). Em 1802 seus moradores puderam votar pela saída dos religiosos e deixar de pagar 1/3 de seus produtos a eles, reinvindicação registrada desde 1767. Portanto, sabe-se que no início do século XIX a população predominante era indígena, com alguns africanos e afrodescendentes, mas sua identidade e demografia ainda são desconhecidas (Calixto, 1927; Petrone 1995).

A Capitania de São Vicente foi uma sociedade escravagista com economia parcialmente movida por cativos indígenas trazidos de fora, retardando a entrada de contingentes consideráveis de africanos escravizados, cujo ingresso mais notório foi apenas no final do século XVIII (Nizza da Silva 2009). Os números do Atlantic Slave Trade Database (www.slavevoyages. org) mostram os ingressos de apenas 4.770 pessoas escravos africanos e afro-brasileiros na região Sudeste do Brasil, no período de 1576-1600. O ingresso aumentou gradativamente ao longo do século XVII: 1. 1601-1625: 32.395; 2. 1626-1650: 48.317; 3. 1651-1675: 68.248; 4. 1676-1700: 72.123. A imensa maioria foi para os estados do Rio de Janeiro e do Espírito Santo.

Apesar do aumento no afluxo de escravos, nossos registros nas coleções de vasilhas inteiras e fragmentos do sudeste de São Paulo não mostram atributos africanos característicos, como os encontrados em Jundiaí por Morales (2001) e em São Sebastião por Agostini (2010). As asas poderiam vir das afroculturas, como sugere Morales, mas elas já ocorriam em contextos anteriores à presença africana, em sítios e áreas coloniais do Rio de Janeiro, 
São Paulo e Rio Grande do Sul. No presente, temos a impressão de que a contribuição africana na cerâmica paulista aparece, eventualmente, em algumas decorações, mas não na morfologia na região Sudeste do estado, de São Vicente para o sul, sendo um tema aberto às pesquisas, onde é necessário compreender as variações das composições demográficas locais e regionais ao longo do tempo, principalmente a partir do século XVIII. Nos séculos XIX e XX, ingressaram no litoral sul pessoas de diversas regiões da Europa e do Japão, formando um contexto regional com sociedades plurais, diversificando a matriz social predominantemente indígena, africana e afro-brasileira e, em menor monta, luso-europeia. Apesar da diversificação cultural, a prática da cerâmica paulista não sofreu mudanças significativas na longa duração, reforçando a nossa hipótese de que seus parâmetros tradicionais foram adotados por quem ingressou na sociedade regional. Nesta altura da pesquisa parece que a agência dos recém-chegados era optar pela mudança, adequando-se para persistir no modo de vida local, eventualmente deixando alguma marca na decoração.

A figura 3 mostra um exemplo de apropriação e transformação inscrito em uma panela da cerâmica paulista encontrada por Araújo (2011) no sítio HCR, município de Itapeva, com datação relativa entre o período colonial e o século XIX. É um caso típico de articulação de tecnologias indígenas e portuguesas nos fundamentos da cerâmica paulista. Quanto à morfologia, apresenta lábio arredondado, borda direta e pescoço vertical, bojo globular e base plano-convexa, comuns nas panelas portuguesas e tupiniquim (nas nha'émpepó médias a pequenas, utilizadas para fazer mingau). A superfície do pescoço foi recoberta com uma placa delgada, decorada com linhas incisas diagonais sobre linhas incisas horizontais (uma releitura do canelado), comumente encontradas na cerâmica comum medieval portuguesa. O tratamento do bojo é corrugado, típico tupiniquim. As duas asas curvilíneas, aplicadas na parte superior do bojo, que no período pré-colonial não eram usadas pelas Tupiniquim, são transformações das asas retilíneas portuguesas. 
Figura 3: Cerâmica Paulista: a) panela, sítio HCR, Museu Histórico de Itapeva (foto de Francisco Silva Noelli); d) perfil da panela do sítio HCR (Araújo 2011). Cerâmica portuguesa (redesenhado de Vieira 2011 e Rodrigues 2014): b) linhas incisas diagonais, séculos $\vee$ a XI, pátio do Museu Grão Vasco, Viseu; c) canelado, séculos IX a XI, sítio S. Gens, Celorico da Beira
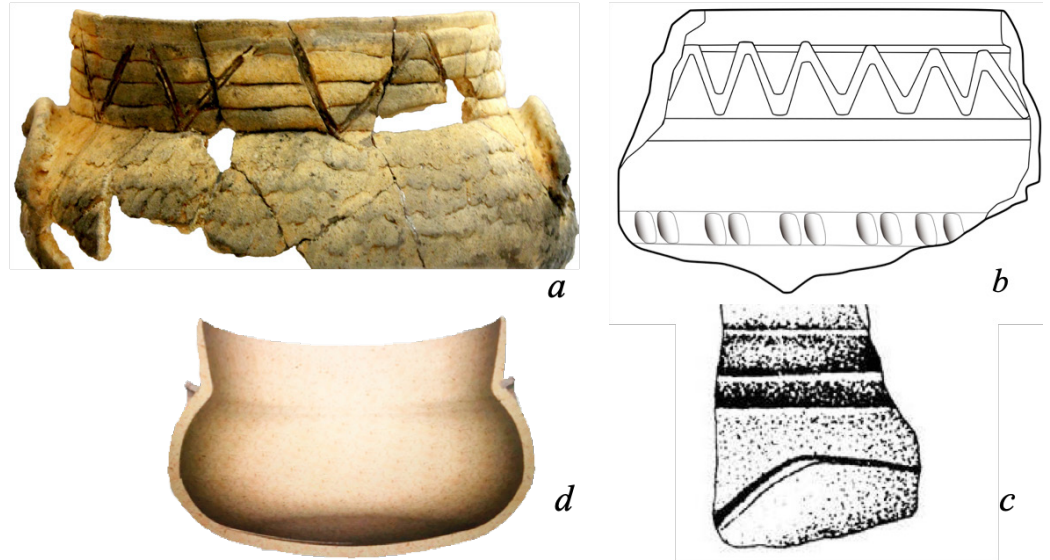

Sem escala

Das Tupiniquim às ceramistas do presente: a persistência de práticas

A cerâmica tupiniquim teve dois estágios cronológicos: 1. pré-colonial (até o século XVII); 2. cerâmica paulista (do século XVI até o presente). Esta cronologia mostra a persistência das práticas cerâmicas e permite considerar que a mudança da tecnologia pré-colonial para colonial não ocorreu de uma hora para outra, pois houve contemporaneidade entre as duas produções por mais de 150 anos. A cerâmica tupiniquim não deixou de ser produzida fora dos territórios dominados pela aliança com os portugueses, enquanto a cerâmica paulista ia gradativamente sendo espalhada pelas integrantes das constelações de comunidades de práticas. Também se deve considerar que o declínio demográfico, a desestruturação da sociedade e dos seus modos de vida causaram contínua diminuição, até o desaparecimento da produção da cerâmica tupiniquim com as suas características pré-coloniais no século XVIII.

É necessário considerar que os núcleos paulistas tiveram oscilações demográficas entre os seus integrantes ao longo do tempo. A tabela 1 mostra que os portugueses sempre foram poucos e que é difícil, especialmente a 
partir do século XVII, distinguir entre os portugueses nascidos na Europa e os filhos deles com as Tupiniquim. Temos um exemplo dessa desproporção em 1610. Jácome Monteiro (citado em Leite 1949:395) relatou que os moradores da vila de São Paulo de Piratininga eram "maioria mamelucos e raros portugueses; e mulheres [portuguesas] há só uma". Pode-se afirmar que a população europeia da Capitania de São Vicente não ultrapassou a média anual de mil pessoas até o ano de 1650, alcançando mil e quinhentas "pessoas de comunhão" em 1672.

Tabela 1. Tamanho da população portuguesa/descendentes na Capitania de São Vicente

\begin{tabular}{|c|c|c|c|}
\hline Ano & Local & $\begin{array}{l}\text { Número de portugueses e } \\
\text { descendentes, conforme os } \\
\text { termos das fontes }\end{array}$ & Fonte \\
\hline 1548 & Capitania de São Vicente & $\begin{array}{l}\text { mais de } 600 \text { "almas, entre } \\
\text { homens, mulheres e } \\
\text { meninos" }\end{array}$ & Góis 1965:262 \\
\hline 1553 & Capitania de São Vicente & ca. 800 homens cristãos & Schmidl 1985:174 \\
\hline 1561 & São VicentelSantos & 300 & $\begin{array}{l}\text { Oficiais da Câmara } \\
\text { 1956:354 }\end{array}$ \\
\hline 1561 & Piratininga & 30 "brancos"/30 "mestiços" & $\begin{array}{l}\text { Oficiais da Câmara } \\
\text { 1956:354 }\end{array}$ \\
\hline 1574 & Capitania de São Vicente & 500 "vizinhos" & Velasco 1894:568 \\
\hline 1576 & Capitania de São Vicente & 500 & Gândavo 1576:37 \\
\hline 1584 & Capitania de São Vicente & 300 & Anchieta 1988:430-431 \\
\hline 1584 & São Vicente & 50 "portugueses" & Anchieta 1988:430 \\
\hline 1584 & Santos & 100 "vizinhos" & Anchieta 1988:430 \\
\hline 1584 & Itanhaém & 30 "vizinhos brancos" & Anchieta 1988:431 \\
\hline 1585 & Piratininga & 120 & Cardim 1934:314 \\
\hline 1585 & São Vicente & 80 & Cardim 1934:316 \\
\hline 1585 & Santos & 80 & Cardim 1934:316 \\
\hline 1585 & Itanhaém & 50 & Cardim 1934:316 \\
\hline C. 1590 & São Vicente/Piratininga & 600 "portugueses" & Soares 1966:11 \\
\hline 1590 & Piratininga & 171 "portugueses" & Sant'anna 1953:9-15 \\
\hline 1590 & Piratininga & 140 & ACSP 1590, v. 1:410 \\
\hline 1606 & Piratininga & 190 & Luís 2004:232 \\
\hline 1606 & Capitania de São Vicente & 700 "portugueses" & Luís 2004:232 \\
\hline C. 1635 & São Vicente & 100 "brancos e mestiços" & Glimmer 2007:269 \\
\hline C. 1635 & Santos & 200 "portugueses e mestiços" & Glimmer 2007:270 \\
\hline c.1635 & Piratininga & 200 "portugueses e mestiços" & Glimmer 2007:274 \\
\hline
\end{tabular}




\begin{tabular}{|l|l|l|l|}
\hline 1640 & Piratininga & 200 & ACSP 1640 \\
\hline 1649 & Piratininga & 200 "portugueses" & Vieira 1958:440 \\
\hline 1672 & Piratininga & 1500 "cristãos brancos" & Carrara 2014 \\
\hline 1672 & Santos & 1000 "cristãos brancos" & Carrara 2014 \\
\hline 1672 & Itanhaém & "muito povoado" & Carrara 2014 \\
\hline 1672 & São Vicente & "muito povoado" & Carrara 2014 \\
\hline 1687 & Vila de São Paulo & 1520 "pessoas de comunhão" & Carrara 2014 \\
\hline 1687 & Santos & 500 "pessoas de comunhão" & Carrara 2014 \\
\hline 1687 & São Vicente & 400 "pessoas de comunhão" & Carrara 2014 \\
\hline 1687 & Itanhaém & 500 "pessoas de comunhão" & Carrara 2014 \\
\hline 1687 & Iguape & 96 "pessoas de comunhão" & Carrara 2014 \\
\hline 1687 & Cananeia & 290 "pessoas de comunhão" & Carrara 2014 \\
\hline 1687 & Paranaguá & 470 "pessoas de comunhão" & Carrara 2014 \\
\hline 1687 & Curitiba & 150 "pessoas de comunhão" & Carrara 2014 \\
\hline
\end{tabular}

\section{A cerâmica paulista e seu contexto de produção}

Esta seção compara os principais aspectos da produção e do uso das cerâmicas (Tabela 2) conforme as fontes históricas e os/as seguintes autora(e)s: 1. tupiniquim (Brochado 1991; Corrêa 2014); 2. portuguesa comum (Fernandes 2012; Bugalhão \& Coelho 2017); 3. cerâmica paulista (Scheuer 1976; Nascimento 1986), mas também se assenta nas análises que realizamos sobre as coleções de vasilhas inteiras e de fragmentos em diversas instituições, como indicamos acima nos objetivos.

Para entender o processo inicial da cerâmica paulista é fundamental considerar que houve uma relação de sociabilidade e mútuas compreensões das tecnologias entre os Tupiniquim e os portugueses. À primeira vista, a morfologia das cerâmicas pré-coloniais tupiniquim tem poucas semelhanças com a cerâmica comum medieval/pós-medieval portuguesa e com a cerâmica paulista, como se verifica na amostra da Figura 4. Mas, observando-se os detalhes, vemos similares alguns atributos morfológicos e os tratamentos de superfície e a seção do perfil da parede da vasilha, conjugando escolhas técnicas de dois modos oleiros, compreendendo: 1. alteridade tupiniquim; 2. apropriação da cerâmica portuguesa pelas ceramistas indígenas; 3 . articulação de práticas cerâmicas com matérias-primas, cadeia operatória, linguagem e usos. 
Figura 4: Comparação entre a cerâmica tupiniquim, portuguesa e paulista. Referências: Cerâmica tupiniquim (fotos de Francisco Silva Noelli): nha'ẽpepó (cortesia do Museu Histórico e Arqueológico de Peruíbe), camucim, nha'ẽ (cortesia do Museu Nacional do Rio de Janeiro); Cerâmica comum medieval/pós-medieval portuguesa: panela, jarro e prato (Gomes 2012); frigideira (Bugalhão \& Coelho 2017); Cerâmica paulista (fotos de Francisco Silva Noelli): panela (coleção Marianne Sallum); jarra, frigideira de esquentar fumo

(cortesia do Museu Casa do Barão, São Vicente); prato (reelaborado de Scheuer, 1976)

\section{Tupi pré-colonial Portuguesa comum Cerâmica Paulista}

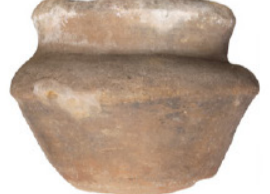

Nha'ẽpepó

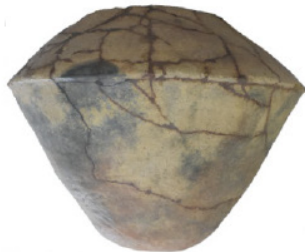

Camucim

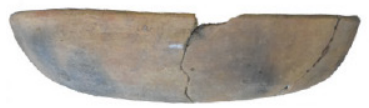

Nha'ẽ

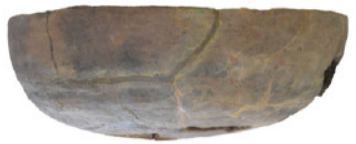

Nha'ẽ
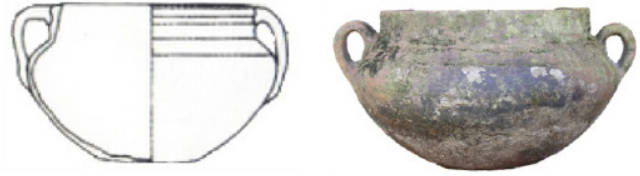

Panela
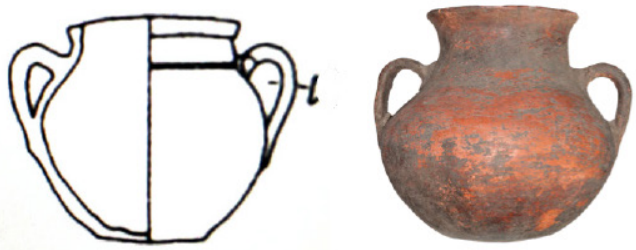

Jarra
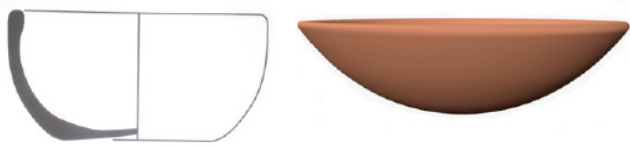

Prato

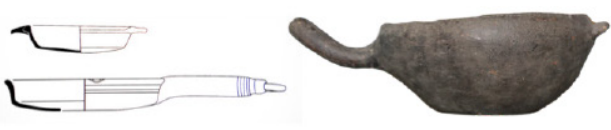

Frigideira

Sem escala 
Entre os Tupiniquim, a produção cerâmica era domínio das mulheres. Em Portugal, a cerâmica é domínio dos homens. E na cerâmica paulista, a produção foi historicamente dominada pelas mulheres e apenas recentemente alguns homens passaram a produzir vasilhas. Em todos estes contextos a formação ocorria nas comunidades de práticas familiares (Fernandes 1975; Fernandes 2012; Scheuer 1976). A organização do trabalho tinha diferentes relações de produção em Portugal, sendo residencial e hierarquizada, com especializações relativas a cada etapa, implicando postos de trabalho remunerados diferentemente sob a liderança do oleiro principal. Nas cerâmicas tupiniquim e paulista a atividade era residencial e uma única mulher executava quase todas as etapas de produção, recebendo alguma ajuda na elaboração de grandes vasilhas e, eventualmente, na localização das jazidas, na extração e no transporte do barro que poderiam ser feitos por quaisquer pessoas.

A produção tupiniquim era essencialmente local e para uso familiar, às vezes colaborativa entre famílias em eventos coletivos. As cerâmicas portuguesas, além do uso familiar, eram fabricadas visando ao comércio com os núcleos urbanos e as redes regionais circunvizinhas. A cerâmica paulista era feita para uso residencial, mas a partir do século XVIII passou a ser comercializada. A produção de cerâmica era fiscalizada, recolhia impostos e recebia permissão do poder real em Portugal. As cerâmicas tupiniquim e paulista tinham na confiança do produto e na estética as condicionantes para a circulação extra residencial, e somente no final do século XVIII foram encontrados indícios de fiscalização e recebimento de pagamento em bens ou dinheiro pelas vasilhas. 
Tabela 2. Contexto de produção

\begin{tabular}{|c|c|c|c|}
\hline $\begin{array}{c}\text { Contexto de } \\
\text { produção }\end{array}$ & Tupiniquim & $\begin{array}{c}\text { Cerâmica } \\
\text { portuguesa }\end{array}$ & Cerâmica paulista \\
\hline Gênero dominante & Feminina & Masculina & Feminina \\
\hline $\begin{array}{l}\text { Estrutura de } \\
\text { trabalho }\end{array}$ & Familiar & Familiar & Familiar \\
\hline Formação & $\begin{array}{l}\text { "Doméstica } \\
\text { Linhagem feminina } \\
\text { Comunidade de } \\
\text { práticas" }\end{array}$ & $\begin{array}{l}\text { "Doméstica } \\
\text { Linhagem masculina } \\
\text { Comunidade de } \\
\text { práticas" }\end{array}$ & $\begin{array}{l}\text { "Doméstica } \\
\text { Linhagem feminina } \\
\text { Comunidade de } \\
\text { práticas" }\end{array}$ \\
\hline $\begin{array}{l}\text { Organização do } \\
\text { trabalho e cadeia } \\
\text { operatória }\end{array}$ & $\begin{array}{l}\text { "Generalista } \\
\text { Domina todas as } \\
\text { etapas, eventual } \\
\text { auxílio na extração } \\
\text { e no transporte de } \\
\text { matéria-prima" }\end{array}$ & $\begin{array}{l}\text { "Hierarquizada } \\
\text { Tarefas } \\
\text { especializadas" }\end{array}$ & $\begin{array}{l}\text { "Generalista } \\
\text { Domina todas as } \\
\text { etapas, eventual } \\
\text { auxílio na extração } \\
\text { e no transporte de } \\
\text { matéria-prima" }\end{array}$ \\
\hline Distribuição & Local & Local/Regional & Local/Regional \\
\hline Atividade & Desregulamentada & $\begin{array}{l}\text { Regulamentada/ } \\
\text { estatal }\end{array}$ & Desregulamentada \\
\hline Permissão & Estética & $\begin{array}{l}\text { Alvará/Exame } \\
\text { Público }\end{array}$ & $\begin{array}{l}\text { Confiança no } \\
\text { produto e estética }\end{array}$ \\
\hline
\end{tabular}

\section{Linguagem}

A linguagem é um tema central, com grande potencial para a compreensão de aspectos da persistência da cerâmica paulista. Provavelmente, as Tupiniquim se apropriaram da tecnologia e das linguagens portuguesas, assim como os portugueses devem ter aprendido as linguagens da materialidade tupiniquim. Contudo, trata-se de um tema inteiramente aberto à pesquisa. Como ponto de partida para orientar a busca nas fontes escritas e interpretar os registros arqueológicos, mostramos na tabela 3 três amostras taxonômicas, de São Paulo, Paraná (Scheuer 1967, 1976, 1982) e Portugal (Fernandes 2012; Bugalhão \& Coelho 2017). Elas aportam subsídios para comparar a língua portuguesa em São Paulo com as extintas línguas tupiniquim e geral paulista. 
Tabela 3. Linguagem da cerâmica paulista e portuguesa

\begin{tabular}{|c|c|c|c|}
\hline $\begin{array}{l}\text { Cerâmica } \\
\text { paulista }\end{array}$ & Função & Cerâmica portuguesa & Função \\
\hline Pote, depósito & Armazenar líquidos & $\begin{array}{l}\text { Cântaro, talha, pote, } \\
\text { bilha }\end{array}$ & Armazenar líquidos \\
\hline Pichorra & Bule para café & $\begin{array}{l}\text { Infusa, Jarra, } \\
\text { Jarrinha, Pichel }\end{array}$ & $\begin{array}{l}\text { Servir líquidos à } \\
\text { mesa }\end{array}$ \\
\hline Boião & $\begin{array}{l}\text { Armazenar líquido, } \\
\text { sal etc. }\end{array}$ & Boião, Potinho & $\begin{array}{l}\text { Armazenar e servir } \\
\text { à mesa alimentos } \\
\text { semissólidos }\end{array}$ \\
\hline Nhaninha & $\begin{array}{l}\text { Transportar líquido } \\
\text { para o local de } \\
\text { trabalho }\end{array}$ & $\begin{array}{l}\text { Cantil, cantimplora, } \\
\text { gorgoleta }\end{array}$ & $\begin{array}{l}\text { Transportar } \\
\text { líquidos durante os } \\
\text { deslocamentos }\end{array}$ \\
\hline Prato & $\begin{array}{l}\text { Guardar/servir } \\
\text { alimentos }\end{array}$ & $\begin{array}{l}\text { Prato, pratel, testo, } \\
\text { trincho }\end{array}$ & $\begin{array}{l}\text { Servir à mesa, } \\
\text { individual, } \\
\text { eventualmente } \\
\text { coletivo nas vasilhas } \\
\text { maiores }\end{array}$ \\
\hline Cuscuzeiro & $\begin{array}{l}\text { Forma para cozinhar } \\
\text { no vapor massa de } \\
\text { cuscuz }\end{array}$ & Cuscuzeiro & $\begin{array}{l}\text { Forma para cozinhar } \\
\text { no vapor massa de } \\
\text { cuscuz }\end{array}$ \\
\hline Panela de mutirão & $\begin{array}{l}\text { Recipiente de maior } \\
\text { capacidade para } \\
\text { cozinhar alimentos }\end{array}$ & $\begin{array}{l}\text { Panela, asado, } \\
\text { caldeirão, púcara }\end{array}$ & Cozinhar alimentos \\
\hline Panela & Cozinhar alimentos & Panela, asado, púcara & Cozinhar alimentos \\
\hline Frigideira & Fritar & $\begin{array}{l}\text { Frigideira, caçarola, } \\
\text { caçoila, sertã }\end{array}$ & Fritar \\
\hline Frigideira & $\begin{array}{l}\text { Para "esquentar" } \\
\text { fumo em rolo }\end{array}$ & & \\
\hline Assadeira & Assar carnes & $\begin{array}{l}\text { Tacho, assadeira, } \\
\text { caçarola, caçoila, } \\
\text { pingadeira, talhador, } \\
\text { terrina }\end{array}$ & $\begin{array}{l}\text { Cozinhar ao fogo ou } \\
\text { ao forno }\end{array}$ \\
\hline Torrador & Torrar café e farinha & & \\
\hline Tampa & Uso na panela & Tampa, testo & Cobrir recipiente \\
\hline
\end{tabular}




\section{Processo de produção cerâmica}

Os três conjuntos possuem semelhanças (Tabela 4). A preparação do barro era dividida em várias etapas, mas predominantemente masculina em Portugal; entre as Tupiniquim e na cerâmica paulista, eram as mulheres que realizavam esta tarefa. O torno e a roda baixa, entre os portugueses, eram fundamentais para levantar a vasilha, mas não foram adotados em São Paulo, onde até o presente predomina o moldado na base com as paredes acordeladas até o lábio.

Tabela 4. Cadeia operatória

\begin{tabular}{|c|c|c|c|}
\hline Atividade & Tupiniquim & $\begin{array}{c}\text { Cerâmica preta } \\
\text { portuguesa }\end{array}$ & Cerâmica paulista \\
\hline Preparação do barro & Feminina & Masculina & Feminina \\
\hline Levantar a peça & $\begin{array}{l}\text { "Modelado/ } \\
\text { acordelado } \\
\text { Feminina" }\end{array}$ & $\begin{array}{l}\text { "Roda Baixa e Torno } \\
\text { Masculina" }\end{array}$ & $\begin{array}{l}\text { "Modelado/ } \\
\text { acordelado } \\
\text { Feminina" }\end{array}$ \\
\hline Pigmentação preta & Inexistente & Argila & Vegetal \\
\hline Polir/brunir & Feminina & Feminina & Feminina \\
\hline Aguada & Feminina & Masculina & Feminina \\
\hline $\begin{array}{l}\text { "Decoração: } \\
\text { Linha incisa } \\
\text { Asa, alça, bico } \\
\text { Cinta/cordão de } \\
\text { barro } \\
\text { Pintura" }\end{array}$ & Feminina & Masculina/Feminina & Feminina \\
\hline Queima & $\begin{array}{l}\text { "Ar livre } \\
\text { Feminina" }\end{array}$ & $\begin{array}{l}\text { "Forno/ar livre } \\
\text { Masculina" }\end{array}$ & $\begin{array}{l}\text { "Forno/ar livre } \\
\text { Feminina" }\end{array}$ \\
\hline Resina vegetal & $\begin{array}{l}\text { "Presente } \\
\text { Feminina" }\end{array}$ & $\begin{array}{l}\text { "Ausente } \\
\text { Inexistente" }\end{array}$ & $\begin{array}{l}\text { "Presente } \\
\text { Feminina" }\end{array}$ \\
\hline Vasilha decorada & $\begin{array}{l}\text { Pintada não vai ao } \\
\text { fogo }\end{array}$ & $\begin{array}{l}\text { Geralmente não vai } \\
\text { ao fogo }\end{array}$ & Incisas vão ao fogo \\
\hline
\end{tabular}

A pigmentação preta da própria argila era usual na metade norte de Portugal, mas desconhecida pelas Tupiniquim no período pré-colonial. Contudo, as evidências mostram que elas começaram a colorir com preto a cerâmica colonial após a primeira queima, para cobrir a paleta de cores avermelhadas, marrons e cremes das argilas regionais (figura 5), usando 
corantes vegetais feitos com cascas de jacatirão (ou cuipeúna) (Tibouchina mutabilis Cogn.) e aroeira (corneíba) (Schinus terebinthifolius Raddi) usadas até o presente (Scheuer 1976; Nascimento 1986). Contudo, alterações químicas pós-deposicionais no contexto arqueológico poderiam mudar a cor preta para tons cinzas, ficando mais claras, como ocorre na cerâmica preta em Portugal (Costa 2014).

Figura 5. Cerâmica paulista tingida com preto no vale do Ribeira-Iguape, c. 1970.

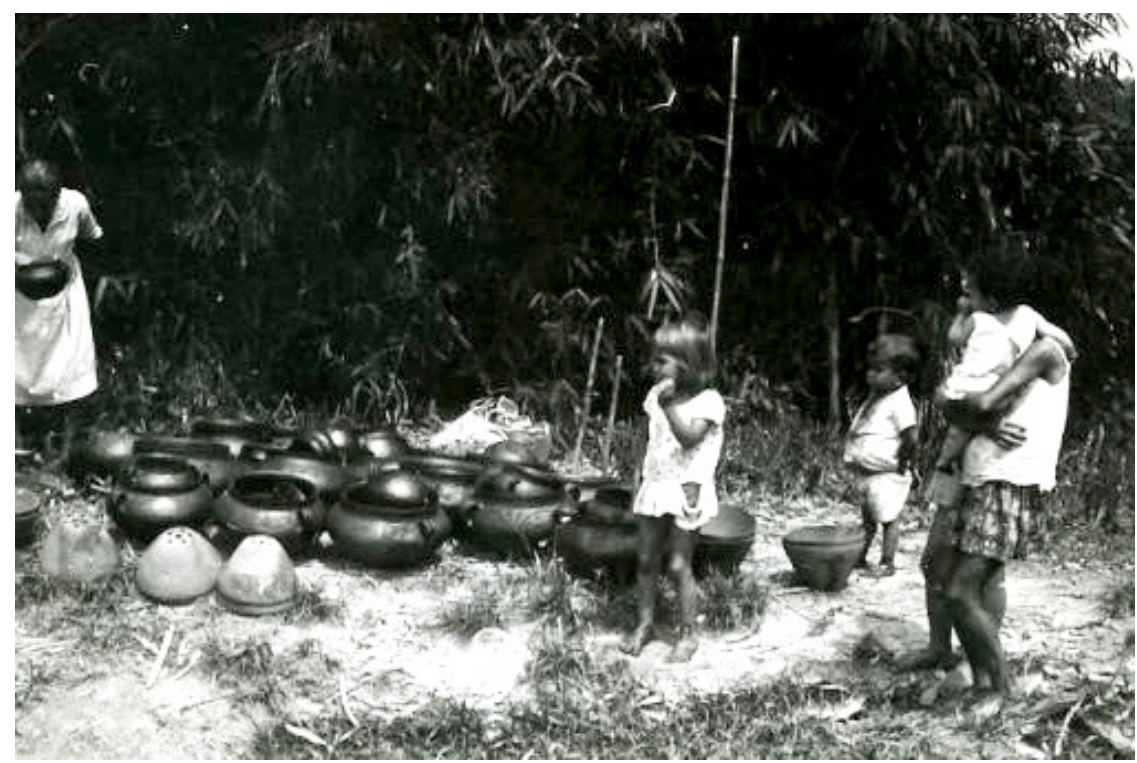

Foto: R. Stulbach, acervo MIS-São Paulo

A peça era polida e/ou brunida pelas portuguesas enquanto tinha consistência de couro. Depois o ceramista dava uma aguada para uniformizar e vedar a parede nos lados interno e externo, com sequência semelhante nas cerâmicas paulista e tupiniquim. A decoração era feita pelas mulheres nos dois lados do Atlântico, sendo eventualmente executada por homens em Portugal. A superfície interna dos três conjuntos cerâmicos era lisa, regularizada e vedada com aguadas de diferentes densidades e espessuras; no caso tupiniquim, algumas classes funcionais recebiam pintura interna, especialmente os pratos coletivos. Na cerâmica portuguesa predominava a superfície externa lisa, com muitas possibilidades decorativas (Bugalhão \& Coelho 2017), recebendo, por exemplo, cordões ou cintas de barro, linhas incisas curvilíneas e diagonais, caneluras, impressões e pintura com motivos florais. A tupiniquim podia ter superfície externa lisa, corrugada, escovada, 
ungulada, ponteada, espatulada, incisa e pintada com motivos geométricos, dependendo da classe funcional. Na pintura empregava-se o taguá, pigmento vermelho composto de óxido de ferro; a tabatinga é o branco, composto por caulim - duas palavras tupiniquim (tagoâ, tobâtínga, Anchieta 1595:14v), depois faladas na língua geral paulista.

Ainda não encontramos dados históricos sobre a definição de barro com a cor preta na língua tupiniquim, sendo mais comum o óxido de manganês no registro arqueológico, usado apenas em linhas retas e curvilíneas sobre fundo branco (Sallum et al. 2018). No entanto, na cerâmica paulista as vasilhas pintadas perderam espaço na segunda metade do século XX devido à dificuldade de acesso aos pigmentos minerais por causa de questões fundiárias, sendo praticamente desconhecidas pelas mais novas (Scheuer 1976). A cerâmica paulista tem a superfície externa lisa, mas algumas eram total ou parcialmente corrugadas, escovadas e estocadas. Também recebiam linhas incisas onduladas, as bordas onduladas e cordões ou cintas de barro decoradas no estilo português (Figura 6). A cerâmica portuguesa tinha alças, asas e bicos; inexistentes na tupiniquim. À cerâmica paulista incorporaram alças, asas e bicos. Existem raros registros arqueológicos de vasilhas tupiniquim com asas e alças fora dos núcleos coloniais, que parecem representar uma opção pela apropriação destes atributos, mas fora dos padrões portugueses, sugerindo que a ceramista não integrava diretamente uma comunidade de práticas coloniais. 
Figura 6. Amostra de atributos semelhantes. Cerâmica paulista (fotos de Francisco Silva Noelli, cortesia do Museu Casa do Barão, São Vicente: a) nhaninha; e) boião; g) frigideira de esquentar fumo; c) fragmento registrado in situ, Morro da Quatinga, Antonina, PR; Medieval portuguesa: b) Lisboa (Santos 2008); d) Coimbra (Ramos et al. 2014); f) Coimbra (Silva 2014); h) Santa Olaia (Nazaré 2013)

São Paulo e Paraná

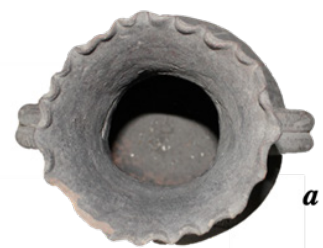

Borda ondulada/boleada

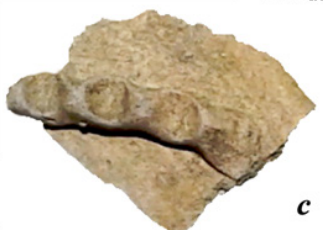

Portugal medieval

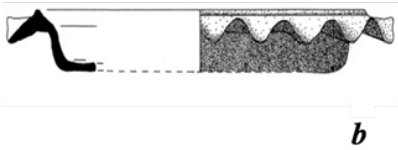

$\boldsymbol{b}$

Aplique/cordão de barro

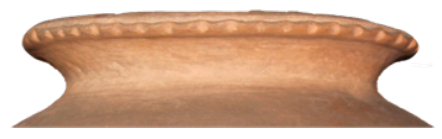

e

Impressão/digitado

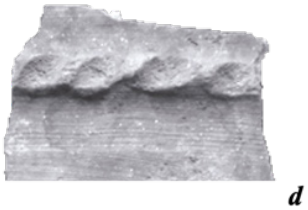

$\boldsymbol{d}$

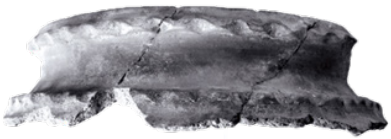

$f$

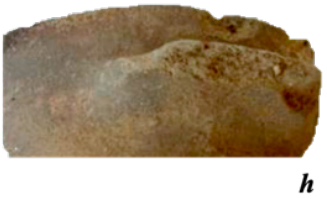

Asa

Sem escala

A queima da cerâmica a céu aberto era usada nas três técnicas: 1. portuguesa: soenga com queima de grandes quantidades de vasilhas, ainda usada até hoje; 2 . tupiniquim: a céu aberto, com poucas vasilhas de cada vez; 3. cerâmica paulista: similar a soenga. O forno é a técnica mais comum entre as cerâmicas portuguesas e paulistas. Em São Paulo, os primeiros registros indiretos do uso de fornos são de 1527-30 e a primeira licença municipal concedida para olaria é de 1575 (Brancante 1981:210). Porém, provavelmente, o seu emprego é anterior, pois desde o final da década de 1520 há relatos sobre objetos cerâmicos, sobretudo construtivos. 
A resina vegetal foi comum nas cerâmicas tupiniquim e paulista, mas não era empregada em Portugal. A sua matéria-prima era a árvore almecegueira ou breu branco, chamada na língua indígena de yvyra ysy (Protium heptaphylum [Aubl.] Marchand), passada aquecida em estado líquido após a queima para concluir a impermeabilização e conferir um aspecto envernizado às superfícies pintadas e, eventualmente, por dentro.

As vasilhas pintadas e envernizadas tupiniquim não eram usadas sobre o fogo, apenas os camucim para fermentar e armazenar cauim eram aquecidos com leve braseiro ao redor da base. As demais iam ao fogo, especialmente as de processar alimentos, às vezes algumas maiores para servir e manter aquecida a refeição. As pintadas portuguesas e paulistas também não iam ao fogo, enquanto as de processar alimentos sim. Nos três casos, as vasilhas de armazenar não iam ao fogo, mas tais situações eram relativas ao uso primário, enquanto no secundário os usos eram variados.

\section{Forma das vasilhas}

As cerâmicas portuguesa e paulista têm mais uniformidade morfológica entre as suas classes funcionais do que possuem com a cerâmica tupiniquim. A maioria apresenta paredes com espessuras finas ou médias (entre 0,4 e 1,5 cm), tanto em vasilhas que vão ao fogo como nas vasilhas usadas para servir e armazenar alimentos e líquidos. Os corpos apresentam formas arredondadas, ovoides, elípticas e tronco-cônicas com contornos complexos, com bases planas ou levemente arredondadas.

Na cerâmica paulista as panelas têm estabilidade morfológica na longa duração, podendo ser divididas em dois conjuntos por tamanho: 1. familiar, com dimensões e volume proporcionais ao número de indivíduos; 2. comunitário, para uso em festas e como parte da reciprocidade de um trabalho de mutirão. Elas têm em comum com as panelas portuguesas um pescoço relativamente estreito, sem reforço na borda, como não havia nas panelas tupiniquim (Figura 7). 
Figura 7. Cerâmicas paulistas de Iguape, Cananeia, Sorocaba e Porto Feliz: cortesia do Museu Casa do Barão, São Vicente: a) pichorra; c) panela; d) nhaninha; e) boião; f) torrador; g) frigideira para esquentar fumo; cortesia do Museu Ferroviário de Sorocaba: b) panela de mutirão; cortesia do Museu Histórico e Pedagógico das Monções: h) cuscuzeiro (fotos: Francisco Silva Noelli)

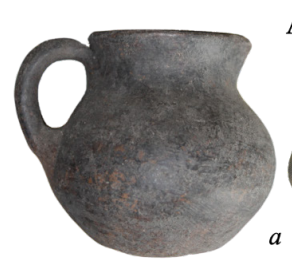

Amostra da cerâmica paulista - séc. XX
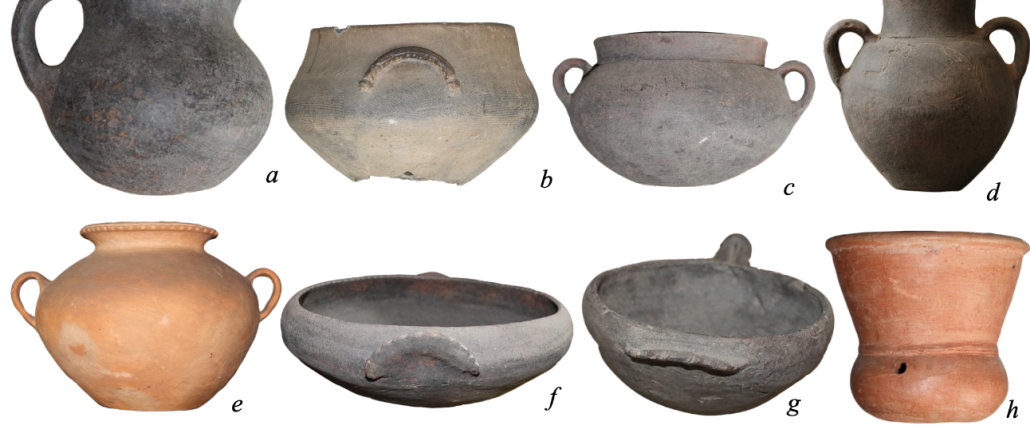

Sem escala

Os jarros, púcaros, cântaros ou talhas no contexto português são usados para conservar e transportar líquidos. Na cerâmica paulista há o depósito, o boião e o pote, que têm morfologia e função similares, corpo ovoide alongado ou globular, base plana e duas alças ou asas. As frigideiras aparecem nas cerâmicas paulista e portuguesa. Elas normalmente têm mais de uma função, dependendo do tamanho e de algumas especificidades tecnológicas, servindo para esquentar fumo em rolo (vasilhas menores), e fritar alimentos (vasilhas maiores), mantendo as características morfológicas. Apresentam, comumente, paredes curvadas com bordas contínuas ou tronco-cônicas, cabos e asas em posições opostas. Em alguns casos, receberam tratamento ondulado nas asas e suas paredes são polidas e tingidas de preto. Já os cabos são formados por rolos duplos e, por vezes, achatados. As asas são curvilíneas e, em alguns casos, ganharam decoração ondulada. O torrador ocorre nas cerâmicas tupiniquim e paulista para processar farinha de mandioca e a torrefação dos grãos de café, mas não na cerâmica portuguesa. 


\section{Conclusão}

As noções de alteridade, apropriação e transformação são fundamentais para compreender a longa duração das práticas cerâmicas em São Paulo, onde a mudança não significou perda, mas persistência cultural. Considerar as relações entre Tupiniquim e portugueses como uma aliança para realizar múltiplos interesses e dedicada a lutar e a escravizar indígenas não tupiniquim permite uma nova possibilidade de investigação, uma vez que os Tupiniquim não foram nem tabula rasa, nem submissos aos portugueses, como quer a produção acadêmica colonizada. A maneira como essas relações foram desenvolvidas na Colônia despertou em parte dos Tupiniquim o desejo de incorporar o outro, tornando as materialidades dos portugueses objetos de predação, da "autotransfiguração" tal como é conhecido na antropologia dos Tupinambá (cf. Viveiros de Castro 1992). Assim se explicaria a transformação da cerâmica pré-colonial depois de 1500.

Mas por que não se percebem modificações pré-coloniais no registro arqueológico de centenas de sítios tupiniquim? Alianças seriam possíveis entre os indígenas antes dos europeus chegarem, talvez semelhantes à estabelecida com os portugueses, cujo desenvolvimento produziria transformações culturais. Evidências linguísticas sugerem a existência de relações pré-coloniais dos Tupi com povos não Tupi, como se verificou no caso Karib (Rodrigues 1985). Mas o desgaste das relações destrataria acordos e levaria a conflitos que, com o tempo, se transformariam em uma espiral de vendetas cíclicas reproduzidas a cada nova geração, tal como sugerem Carneiro da Cunha e Viveiros de Castro (1985). E a vingança poderia ser a causa para não modificar a materialidade, pois o destrato ancestral de uma aliança, continuamente recordado, talvez reafirmasse o desinteresse em se apropriar ou transformar objetos dos outros indígenas. A vingança seria uma "técnica de memória" singular, um "processo de circulação perpétua da memória entre os grupos inimigos, e ela se define, em vários sentidos, como memória dos inimigos" (Carneiro da Cunha \& Viveiros de Castro 1985:205). A circulação perpétua da memória poderia estar entre as causas prováveis da não modificação da cerâmica pré-colonial. Assim como a memória resultava na espiral de vinganças, também poderia causar a evitação de símbolos emblemáticos do inimigo, especialmente de objetos centrais na vida cotidiana e na cosmologia, como são as vasilhas cerâmicas.

Desta forma, a cerâmica paulista emergiu de uma aliança que inaugurou um processo de renovação e ampliação da materialidade, conjuntamente com outros hábitos dietéticos e novas práticas introduzidas pelos europeus de processar alimentos com plantas e animais. Assim, os portugueses e 
suas coisas foram apropriados e transformados pela alteridade tupiniquim. Por outro lado, os europeus se apropriaram de plantas, animais, minerais, materialidades e práticas indígenas, e os transformaram, alterando definitivamente a vida cotidiana e econômica na Europa e nos outros continentes.

A identidade das gerações de ceramistas paulistas precisa ser desvendada, especialmente a partir do século XVIII. Ainda existe um vazio epistemológico no meio acadêmico, tornando-se necessário compreender, tal como propôs John Monteiro(2001:9), como "os jogos de identidade ora distanciavam, ora aproximavam os paulistas de suas origens indígenas".

O fato de as vasilhas e dos fragmentos conhecidos da cerâmica paulista de vários lugares terem entre si mais semelhanças que diferenças sugere que o processo de produção começou nos primeiros núcleos coloniais litorâneos e a sua prática acompanhou as pessoas que foram fundando novos núcleos coloniais, sucessivamente estabelecendo redes de colaboração e trocas entre os assentamentos, aspecto central da sociabilidade tupiniquim. A articulação de conhecimentos e a memória parecem ser o alicerce atemporal da persistência da cerâmica tupiniquim até o presente.

Recebido em: 14 de agosto de 2019

Aprovado em: 30 de outubro de 2019 


\section{Agradecimentos}

À Capes (bolsa doutorado - Processo 99999.002889/2015-03), CNPq (bolsa pós-doutorado - Processo 150312/2018-0). Os autores começaram em outubro de 2017 a pesquisa agora publicada, unindo duas perspectivas sobre a colonização que se beneficiaram mutuamente de suas diferenças. À Daniella M Amaral, pela indicação do livro de Herta Scheuer. A John Manuel Monteiro, in memoriam, pelos debates acalorados sobre os primeiros tempos da sociedade paulista. A Steve Silliman e Lúcio Menezes Ferreira, pelas detalhadas revisões e contribuições. Agradecemos às sugestões da(o) s amiga(o)s Fabíola Silva, Ângelo A. Corrêa, Gregório Ceccantini, Carolina Guedes, Plácido Cali, Marcos André T. Souza, Ângela Buarque, Carlos Lazcano, Astolfo G. M. Araújo, Camila Jácome, Amílcar de Mello D Ávila, Amílcar Guerra, Andréa Catrópa, Andréa Pedro, José Luís de Morais, Sílvio Araújo e Marisa Afonso. Ao Museu de Arqueologia e Etnologia da Universidade de São Paulo, especialmente Dária Barreto, Paulo Jacob, Regivaldo L. da Silva e Cristina Demartini. À Prefeitura de Peruíbe e a Fátima Pires pelo apoio à pesquisa no município. Às instituições que nos receberam para documentar suas coleções musealizadas em São Paulo, Rio de Janeiro, Mato Grosso do Sul e Paraná. Aos pareceristas anônimos da Mana, pelos comentários e sugestões valiosas. 
Francisco Silva Noelli é mestre em História Ibero-Americana pela Pontifícia Universidade Católica do Rio Grande do Sul e, atualmente, doutorando em Arqueologia na Universidade de Lisboa. É pesquisador fundador do Laboratório de Arqueologia, Etnologia e Etno-História da Universidade Estadual de Maringá, e pesquisador associado do Lapis, na Universidade do Extremo Sul-Catarinense. É arqueólogo e historiador de temas diversos sobre as populações Guarani, Jê do sul do Brasil e Tupiniquim, atualmente investigando o processo de construção colonial da sociedade paulista.

https://orcid.org/0000-0003-0267-583X

Endereço institucional: Alameda da Universidade, 1600-214, Lisboa, Portugal. E-mail: francisconoelli@edu.ulisboa.pt

Marianne Sallum é pós-doutoranda no Museu de Arqueologia e Etnologia da Universidade de São Paulo. Doutora e mestre em Arqueologia na mesma universidade. É pesquisadora do Lapgeo - Laboratório de Arqueologia da Paisagem e Geoarqueologia (MAE/USP) e investigadora visitante no UNIARQ, Universidade de Lisboa. É arqueóloga e arte-educadora, investigando temas sobre colonialismo, agência, identidade e práticas cerâmicas, com ênfase nas comunidades Tupiniquim do litoral sul de São Paulo. Desenvolve estudos comparativos de colonialismo com os Estados Unidos e México. https://orcid.org/0000-0001-9210-2044

Endereço institucional: Av. Prof. Almeida Prado, 1466, São Paulo/SP, Brasil, CEP 05508-070. E-mail: marisallum@usp.br 


\section{Referências bibliográficas}

AGOSTINI, Camila. 2010. "Panelas e paneleiras de São Sebastião: um núcleo produtor e a dinâmica social e simbólica de sua produção nos séculos XIX e XX". Vestígios, Revista Latino-Americana de Arqueologia Histórica, 4 (2):127-144.

ALBERT, Bruce. 2002. Cosmologias do contato no Norte-Amazônico. In: B. Albert \& A. Ramos (eds.), Pacificando o branco: cosmologias do contato no Norte-Amazônico. São Paulo: Edunesp/Ioesp. pp. 9-21.

ALENCASTRO, Luíz. 2000. O Trato dos viventes. Formação do Brasil no Atlântico Sul. Séculos XVI e XVII. São Paulo: Cia das Letras.

AMARAL, Daniella. 2012. Loiça de barro do agreste: um estudo etnoarqueológico da cerâmica histórica pernambucana. Dissertação de Mestrado em Arqueologia, São Paulo, Museu de Arqueologia e Etnologia, Universidade de São Paulo.

ANCHIETA, José. 1595. Arte de gramática da lingoa mais vsada na costa do Brasil. Coimbra: António de Mariz. . 1988. Cartas, informações, fragmentos históricos e sermões. São Paulo: Edusp.

ARAÚJO, Sílvio. 2011. Conhecer para preservar: Arqueologia e inclusão social na bacia do Paranapanema superior. Tese de Doutorado em Arqueologia, São Paulo, Museu de Arqueologia e Etnologia, Universidade de São Paulo.

ATALAY, Sonya. 2008. "No Sense of the Struggle: Creating a Context for Survivance at the National Museum of the American Indian". In: A. Lonetree \& A. Cobb-Greetham (eds.), The National Museum of the American Indian: critical conversations. Lincoln: University of Nebraska Press. pp. 67-89.
BATTLE-BAPTISTE, Withney. 2011. Black Feminist Archaeology. Walnut Creek: Left Coast.

BRANCANTE, Eldino. 1981. O Brasil e a cerâmica antiga. São Paulo: Lythographica Ypiranga.

BROCHADO, José. 1991. "What did the Tupinambá cook in their vessels? A humble contribution to ethnographic analogy". Revista de Arqueologia, 6:40-88.

BUGALHÃO, Jacinta \& COELHO, Inês. 2017. "Cerâmica moderna de Lisboa: proposta tipológica". In: A. Caessa; C. Nozes; I. Cameira \& R. Silva (eds.), I Encontro de Arqueologia de Lisboa: uma cidade em escavação. Lisboa: CAL/DPC/DMC/CML. pp. 106-145.

CALI, Plácido. 1999. O Processo de povoamento do litoral sul de São Paulo: Jureia-Itatins. Dissertação de Mestrado em Arqueologia, São Paulo, Museu de Arqueologia e Etnologia, Universidade de São Paulo.

CALIXTO, Benedito. 1927. Capitanias Paulistas. São Paulo: Duprat e Mayenca.

CARDIM, Fernão. 1934. Tratados da terra e gente do Brasil. São Paulo: Cia Editora Nacional.

CARNEIRO DA CUNHA. Manuela \& VIVEIROS DE CASTRO, Eduardo. 1985. "Vingança e temporalidade: os Tupinamba". Journal de la Société des Américanistes, 71:191-208.

CARNEIRO DA CUNHA, Manuela. 2002. "Apresentação". In: B. Albert \& A. Ramos, (eds.), Pacificando o branco: cosmologias do contato no Norte-Amazônico. São Paulo: Edunesp/Ioesp. pp. 7-8.

CARRARA, Ângelo. 2014. "A população do Brasil, 1570-1700: uma revisão historiográfica". Tempo, 20:1-21. 
CIPOLLA, Craig N.; QUINN, James \& LEVI, Jay. 2018. "Theory in collaborative indigenous archaeology: insights from Mohegan". American Antiquity, 84 (1):1-16.

COHN, Bernard. 1986. An Anthropologist among the Historians and other essays. Oxford: Oxford University Press.

COOPER, Frederick. 2005. Colonialism in question. Theory, Knowledge, History. Berkeley: University of California Press.

CORRÊA, Ângelo. 2014. Pindorama de Mboia e Iakaré: continuidade e mudança na trajetória das populações Tupi. Tese de Doutorado em Arqueologia, São Paulo, Museu de Arqueologia e Etnologia, Universidade de São Paulo.

COSTA, Bruno. 2014. A Cerâmica Preta do Mosteiro de São João de Tarouca. Dissertação de Mestrado em Arqueologia, Lisboa, Universidade Nova de Lisboa.

DAWDY, Shannon. 2005. "Thinkertinkers, race, and the archaeological critique of modernity". Archaeological Dialogues, 12 (2):143-164.

DÓRIA, Carlos \& BASTOS, Marcelo. 2018. A culinária caipira da Paulistânia. São Paulo: Três Estrelas.

EWBANK, Thomas. 1856. Life in Brazil; or, a journal of a visit to the land of cocoa and palm. New York: Harper $\&$ Brothers.

FAUSTO, Carlos \& HECKENBERGER, Michael. 2007. "Indigenous History and the History of the 'Indians'". In: (eds.), Time and Memory in Indigenous Amazonia: Anthropological Perspectives. Gainesville: University Press of Florida. pp. 1-43.

FERNANDES, Florestan. 1975. Estudos de etnologia e outros ensaios. Petrópolis: Vozes.
FERNANDES, Isabel. 2012. A loiça preta em Portugal: estudo histórico, modos de fazer e de usar. Tese de Doutorado em História, Braga, Instituto de Ciências Sociais, Universidade do Minho. FEROS, Antonio. 2017. Speaking of Spanish: the evolution of race and nation in the Hispanic World. Cambridge: Harvard University Press.

FERREIRA, Lúcio M. 2015. Arqueología de la diáspora Africana en Sudamérica. Desarrollo, problemáticas y perspectivas. Revista de Arqueología Histórica Argentina y Latinoamericana, 9(2):27-31.

. \& FUNARI, Pedro. 2015. "The Archaeology of Slavery Resistance in Ancient and Modern Times: an initial outlook from a Brazilian Perspective". In: K. Hayes \& C. Cipolla (eds.), Rethinking Colonialism: comparative archaeological approaches. Gainesville: University Press of Florida. pp. 190-209.

FUNARI, Pedro \& SENATORE, María. 2015. "Introduction: Disrupting the Grand Narrative of Spanish and Portuguese Colonialism". In: __ (eds.), Archaeology of Culture Contact and Colonialism in Spanish and Portuguese America. New York: Springer. pp. 1-18.

GÂNDAVO, Pedro. 1576. Tratado da Terra do Brasil - história da província Santa Cruz. Lisboa: António Gonsalvez.

GLIMMER, Wilhelm. 2007. "Situação da Capitania de São Vicente". In: J. de Laet, Roteiro de um Brasil desconhecido. Descrição das costas do Brasil. Rio de Janeiro: KAPA. pp. 266-289.

GÓIS, Luís. 1965. "Carta de Luís de Góis a D. João III de Portugal". In: S. Leite (ed.), Novas páginas de História do Brasil. São Paulo: Cia Editora Nacional. pp. 261-263. 
GOLDMAN, Márcio. 2017. "Contra discursos afroindígenas sobre mistura, sincretismo e mestiçagem: estudos etnográficos". Revista de Antropologia da Universidade Federal de São Carlos, 9 (2):11-28.

GOMES, Rosa. 2012. "A Arqueologia da Idade Moderna em Portugal - contributos e problemáticas". O Arqueólogo Português, Série 5, 2: 13-75.

GOSDEN, Chris. 2004. Archaeology and Colonialism. Cultural Contact from 500 BC to the Present. Cambridge: Cambridge University Press.

HARTEMAN, Gabby \& MORAES, Irislane. 2018. "Contar histórias e caminhar com ancestrais: por perspectivas afrocentradas e decoloniais na arqueologia". Vestígios, Revista Latino-Americana de Arqueologia Histórica, 12 (2):9-34.

HAYES, Katherine \& CIPOLLA, Craig. 2015. "Introduction: Re-imagining Colonial Pasts, Influencing Colonial Futures". In: __ (eds.), Rethinking Colonialism: comparative archaeological approaches. Gainesville: University Press of Florida. pp. 1-16. HOWARD, Catherine. 2002. "A domesticação de mercadorias: Estratégias Waiwai". In: B. Albert \& A. Ramos (eds.), Pacificando o branco: cosmologias do contato no Norte-Amazônico. São Paulo: Edunesp\Ioesp. pp. 5-61. JOHNSON, Matthew. 2006. "On the Nature of Theoretical Archaeology and Archaeological Theory". Archaeological Dialogues, 13 (2):117-132.

LA SALVIA, Fernando \& BROCHADO, José P. 1989. Cerâmica Guarani. Porto Alegre: Pozenato Arte \& Cultura.

LAGROU, Els. 2013. "No caminho da miçanga: arte e alteridade entre os ameríndios". Enfoques - Revista dos Alunos do PPGSA-UFRJ, 12 (1):18-49.
LAW PEZZAROSSI, Heather \& SHEPTAK, Russell. 2019. "Introduction". In:__ (eds.), Indigenous persistence in the colonized Americas: material and documentary perspectives on entanglement. Albuquerque: University of New Mexico Press. pp. 1-18.

LEITE, Fabiana. 2013. A língua geral paulista e o "vocabulário elementar da língua geral brasílica". Dissertação de Mestrado em Linguística, Campinas, Instituto de Estudos da Linguagem, Universidade Estadual de Campinas.

LEITE, Serafim. 1938. História da companhia de Jesus no Brasil. Vol. 1. Rio de Janeiro: Civilização Brasileira/ INL.

1949. História da Companhia de Jesus no Brasil. Vol. 8. Rio de Janeiro: Civilização Brasileira/INL.

LIEBMANN, Matthew. 2015. "The Mickey Mouse Kachina and other 'double objects': Hibridity in the material culture of colonial encounters". Journal of Social Archaeology, 15 (3):1-35.

LIGHTFOOT, Kent. 1995. "Culture Contacts Studies: Redefining the Relationships between Prehistoric and Historical Archaeology". American Antiquity, 60 (2):199-217.

. 2005. Indians, Missionaries, and Merchants: the legacy of colonial encounters on the California frontiers. Berkeley: University of California Press.

LIMA, Tânia. 2002. "Os marcos teóricos da arqueologia histórica, suas possibilidades e limites". Estudos IberoAmericanos, 28 (2):7-23.

LOREN, Diana. 2013. "Considering Mimicry and Hybridity in Early Colonial New England: Health, Sin and the Body 'Behung with Beades'". Archaeological Review from Cambridge, 8 (1):151-168. 
LUÍS, Washington. 2004. Na Capitania de São Vicente. Brasília: Senado Federal.

MONTEIRO, John. 1994. Negros da Terra. Índios e Bandeirantes nas origens de São Paulo. São Paulo: Companhia das Letras.

. 2001. Tupis, tapuias e historiadores: estudos de história indígena e do indigenismo. Tese de Livre-Docência, Campinas: Universidade de Campinas.

MORALES, Walter. 2001. "A cerâmica 'neo-brasileira' nas terras paulistas: um estudo sobre as possibilidades de identificação cultural através dos vestígios materiais na vila de Jundiaí do século XVIII". Revista do Museu de Arqueologia e Etnologia, 11:165-187.

MORALES, Walter \& MOI, Flávia. 2008. "Índios e africanos no interior paulista: um estudo sobre a transição do cativeiro indígena para a escravidão na vila de Jundiaí, SP, no século XVIII". Revista do Museu de Arqueologia e Etnologia, 18:115-131.

MOURA, Herbert \& ALLEN, Scott. 2015. "O Gosto do Barro: Memória culinária e morfologia das cerâmicas utilitárias de Pernambuco". Vestígios. Revista Latino-Americana de Arqueologia Histórica, 9:9-32.

MUNIZ, Tiago, S. \& GOMES, Denise. 2017. "Identidades materializadas na Amazônia colonial: a cerâmica dos séculos XVIII e XIX no sítio Aldeia, Santarém, PA". Vestígios, Revista Latino-Americana de Arqueologia Histórica, 11 (2):53-76.

NASCIMENTO, Haydée. 1986. "Cerâmica folclórica em Apiaí". Revista do Arquivo Municipal, 186:45-121.

NAZARÉ, Maria. 2013. Cerâmicas medievais de Santa Olaia (Figueira da Foz) depositadas no Museu Municipal Dr. Santos Rocha. Relatório de Mestrado, Coimbra, Universidade de Coimbra.
NEWSTEAD, Sarah \& CASIMIRO, Tania. 2015. "A Cerâmica Portuguesa no Atlântico Norte (séculos XVII-XVIII): o iniciar de um projecto de investigação". Almadan, II Série, 19:64-69.

NIZZA da SILVA, Maria; BACELLAR, Carlos; GOLDSCHMIDT, Eliano \& NEVES, L. 2009. História de São Paulo Colonial. São Paulo: Edunesp.

NOELLI, Francisco \& BROCHADO, José. 1998. "O cauim e as beberagens dos Guarani e Tupinambá: equipamentos, técnicas de preparação e consumo". Revista do Museu de Arqueologia e Enologia, 8:117-128.

NOELLI, Francisco \& FERREIRA, Lúcio. 2007. "A persistência da teoria da degeneração indígena e do colonialismo nos fundamentos da Arqueologia Brasileira". História, Ciências, Saúde - Manguinhos 14 (4):1239-1264.

OFICIAIS DA CÂMARA. 1956. Carta dos oficiais da Câmara de São Paulo para D. Catarina. São Paulo, 20 de maio de 1561. In: J. Cortesão (ed.), Pauliceae Lusitana Monumenta Histórica. Vol. 1 (1494-1600), V-VIII partes. Lisboa: Real Gabinete Português de Leitura no Rio de Janeiro. pp. 351-355.

PANICH, Lee. 2013. "Archaeologies of persistence: reconsidering the legacies of colonialism in Native North America". American Antiquity, 78 (1):105-122.

PANICH, Lee; ALLEN, Rebecca \& GALVAN, Andrew. 2018. "The archaeology of Native American persistence at mission San José". Journal of California and Great Basin Anthropology, 38 (1):11-29.

PERRONE-MOISÉS, Beatriz. 2014. "Performed Alliances and Performative Identities Tupinambá in the Kingdom of France". In: L. Graham (ed.), Performing Indigeneity. Global histories and Contemporary Experiences. Lincoln: University of $\mathrm{Ne}$ braska Press. pp. 110-135. 
PETRONE, Pasquale. 1995. Aldeamentos paulistas. São Paulo: Edusp.

RADULET, Carmen. 1991. "Política e mitos edênicos num relato da expedição de 1533 de Martim Afonso de Sousa". In: ___, Os descobrimentos portugueses e a Itália: ensaios filológico-literários e historiográficos. Lisboa: Veja. pp. 92-113.

RAMOS, Mafalda; ALBUQUERQUE, Elisa \& SANTOS, Constança, S. 2014. "Cerâmica dos séculos IX-XII: alguns exemplares provenientes do pátio das escolas da Universidade de Coimbra". In: A. de Man \& C. Tente (eds.), Estudos de Cerâmica Medieval. O Norte e Centro de Portugal séculos XI a XII. Coimbra: Instituto de Estudos Medievais. pp. 69-78.

RIBEIRO, Loredana \& JÁCOME, Camila. 2014. "Tupi ou não Tupi? Predação material, ação coletiva e colonialismo no Espírito Santo, Brasil". Boletim do Museu Paraense Emílio Goeldi, Ciências Humanas, 9 (2):465-486.

RIZVI, Uzma. 2008. "Decolonizing Methodologies as Strategies of Practice: Operationalizing the Postcolonial Critique in the Archaeology of Rajasthan". In: M. Liebmann \& U. Rizvi (eds.), Archaeology and the postcolonial critique. Lanham: Altamira Press. pp. 109-128.

RODRIGUES, Aryon. 1985. "Evidence for Tupi-Carib relationships". In: H. E. Klein \& L. R. Stark (eds.), South American Indian Languages: retrospect and prospect. Austin: University of Texas Press. pp. 371-404.

RODRIGUES, Aryon \& CABRAL, Ana. 2002. "Revendo a classificação interna da família Tupi-Guarani". In: (eds.), Anais do Encontro Internacional do Grupo de Trabalho sobre Línguas Indígenas da ANPOLL. Vol. 1. Belém: UFPA. pp. 327-337.
2012. "Tupían". In: L. Campbell \& V. Grondona (eds), The indigenous languages of South America. Vol. 2. Berlin: Mouton de Gruyter. pp. 495-574.

RODRIGUES, Jerônimo. 1940. "A missão dos Carijós". In: S. Leite (ed.), Novas Cartas Jesuíticas. São Paulo: Cia Editora Nacional. pp. 196-246.

RODRIGUES, Patrícia. 2014. "Cerâmicas medievais do Pátio do Museu Grão Vasco (Viseu): elementos para uma sistematização da cerâmica pleno medieval do espaço viseense. In: A. de Man \& C. Tente (eds.), Estudos de Cerâmica Medieval. O Norte e Centro de Portugal-séculos XI a XII. Coimbra: Instituto de Estudos Medievais. pp. 141-159.

RUBERTONE, Patricia. 2000. "The historical archaeology of Native Americans". Annual Review of Anthropology, 9:425-46.

SAINT-HILAIRE, Auguste. 1995. Viagem pela comarca de Curitiba. Curitiba: Fundação Cultural.

SALLUM, Marianne. 2018. Colonialismo e ocupação tupiniquim no litoral sul de São Paulo: uma história de persistência e prática cerâmica. Tese de Doutorado em Arqueologia, São Paulo, Museu de Arqueologia e Etnologia, Universidade de São Paulo.

SALLUM, Marianne; APPOLONI, Carlos; BUTRÓN, Agustín; CECCANTINI, Gregório \& AFONSO, Marisa. 2018. "Estudos de pigmento, pasta e vestígios químicos de cerâmica associados aos povos Tupi do sítio Gramado (Brotas, São Paulo - Brasil)". Cadernos do Lepaarq, 15 (30):191-218.

SANT'ANNA, Nuto. 1953. Metrópole, Histórias da cidade de São Paulo. Vol. 3. São Paulo: Coleção Departamento de Cultura. 
SANTOS, Patrícia A. 2008. "Cerâmicas de cronologia moderna do edifício do Aljube em Lisboa". Revista Portuguesa de Arqueologia, 11 (2):325-345.

SCHEUER, Herta L. 1967. "Estudo de um núcleo de cerâmica popular". Arquivos do Museu Paranaense 1, Curitiba.

1976. Estudo da cerâmica popular do Estado de São Paulo. São Paulo: Conselho Estadual de Cultura. 1982. A Tradição da cerâmica popular. São Paulo: Escola de Folclore/ Livramento.

SCHMIDL, Ulrich. 1985. "Relación del Viaje al Río de la Plata". In: Luíz López (ed.), Alemanes en América. Madrid: Historia 16. pp. 129-225.

SCHMIDT, Peter \& MROZOWSKI, Stephen. 2013. "The Death of Prehistory Reforming the Past, Looking to the Future". In: (eds.), The Death of Prehistory Reforming the Past, Looking to the Future. Oxford: Oxford University Press. pp. 1-32.

SHEPTAK, Russell; JOYCE, Rosemary \& BLAISDELL-SLOAN, Kira. 2010. "Pragmatic choices, Colonial lives: resistance, ambivalence, and Appropriation in Northern Honduras". In: M. Liebmann \& M. Murphy (eds.), Enduring conquests: rethinking the archaeology of resistance to Spanish colonialism in the Americas. Santa Fe: School for Advanced Research Press. pp. 149-173.

SILLIMAN, Stephen. 2001. "Agency, practical politics and the archaeology of culture contact". Journal of Social Archaeology, 1 (2):190-209.

. 2009. "Change and Continuity, Practice and Memory: Native American Persistence in Colonial New England". American Antiquity, 74 (2):11-230.
2012. "Between the longue durée and the short purée. Postcolonial Archaeologies of Indigenous History". In: M. Oland; S. Hart \& L. Frink (eds.), Colonial North America. Decolonizing Indigenous Histories: Exploring Prehistoric/Colonial Transitions in Archaeology. Tucson: The University of Arizona Press. pp. 113-132.

2015. "A requiem for hybridity? The problem with Frankenstein, purées, and mules". Journal of Social Archaeology, 15 (3):1-22.

SILVA, Fabíola \& NOELLI, Francisco. 2015. "Mobility territorial occupation of the Asurini do Xingu: archeology of recent past in the Amazon". Latin American Antiquity, 26 (4):493-511.

SILVA, Fabíola. 2013. "Tecnologias em transformação: inovação e (re)produção dos objetos entre os Asurini do Xingu". Boletim Museu Emílio Goeldi, Ciências Humanas, 8 (3):729-744.

SILVA, Ricardo. 2014. "A cerâmica dos níveis alto-medievais do fórum de Aeminium (MNMC, Coimbra). In: A. de Man \& C. Tente (eds.), Estudos de Cerâmica Medieval. O Norte e Centro de Portugal - séculos XI a XII. Coimbra: Instituto de Estudos Medievais. pp. 79-98.

SOARES, Francisco. 1966. Coisas notáveis do Brasil. Rio de Janeiro: Instituto Nacional do Livro.

SOUSA, Pero L. 1994. "Diário da navegação de Pero Lopes de Sousa (1530-1532)". In: M. C. Guirado, Relatos do descobrimento do Brasil - as primeiras reportagens. Lisboa: Instituto Piaget.

SOUZA, Marcos. 2013. "Introdução: Arqueologia da diáspora africana no Brasil". Vestígios: Revista Latino-Americana de Arqueologia Histórica, 7 (1):9-19. 
2017. "Arqueologia dos grupos indígenas em contextos históricos: problemas e questões". Revista de Arqueologia, 30 (1):144-153.

. ; LIMA, Tânia A. 2017. Hibridismo e inovação em cerâmicas coloniais do Rio de Janeiro, séculos XVII e XVIII. Urbania, 5:21-60.

SYMANSKI, Luís C. 2010. "Cerâmicas, identidades escravas e crioulização nos engenhos de Chapada dos Guimarães (MT)". História, 14 (3):295312.

SYMANSKI, Luís C. \& GOMES, Denise. 2012. "Mundos mesclados, espaços segregados: cultura material, mestiçagem e segmentação no sítio Aldeia em Santarém (PA)". Anais do Museu Paulista, nova série, 20 (2):53-90.

VELASCO, Juan. 1894. "Geografía y descripción universal de las Indias". Boletín de la Sociedad Geográfica de Madrid, Madrid.

VIEIRA, Ana Isabel. 2011. "Cerâmicas dos séculos XIV a XVI do Castelo de Sesimbra". O Arqueólogo Português, série V (1):657-687.

VIEIRA, Antônio. 1958. "Carta ao Padre Provincial do Brasil sobre a bandeira de Raposo Tavares". In: J. Cortesão, Raposo Tavares e a formação territorial do Brasil. Rio de Janeiro: Ministério da Educação e Cultura/Serviço de Documentação. pp. 439-449.
VIVEIROS de CASTRO, Eduardo. 2001. "GUT Feelings about Amazonia: Potential Affinity and the Construction of Sociality". In: Laura M. Rival \& Neil L. Whitehead (eds.), Beyong the visible and the material: The Amerindianization of society in the work of Peter Rivière. Oxford University Press. pp. 19-45.

. 1992. "O mármore e a murta: Sobre a inconstância da alma selvagem". Revista de Antropologia, 35:21-74.

. 2004. "Exchanging perspectives: The transformation of objects into subjects in Amerindian ontologies". Common Knowledge, 10 (3):463-484. VOSS, Barbara. 2008. The archaeology of ethnogenesis. Race and sexuality in colonial San Francisco. Los Angeles: University of California Press.

WENDRICH, Wilecke. 2012. "Archaeology and apprenticeship: body knowledge, identity, and communities of practice". In: __ (ed.), Archaeology and apprenticeship, body knowledge, identity, and communities of practice. Tucson: The University of Arizona Press. pp. 1-19.

ZANETTINI, Paulo. 2005. Maloqueiros e seus Palácios de Barro: o Cotidiano Doméstico na Casa Bandeirista. Tese de Doutorado em Arqueologia, São Paulo, Museu de Arqueologia e Etnologia, Universidade de São Paulo. 


\section{A CERÂMICA PAULISTA: CINCO SÉCULOS DE PERSISTÊNCIA DE PRÁTICAS TUPINIQUIM EM SÃO PAULO E PARANÁ, BRASIL}

\section{Resumo}

\begin{abstract}
A Arqueologia do Colonialismo no Brasil tem sido concebida na última década na tentativa de descolonizar o seu campo de pesquisa. Passou a perceber e a construir histórias de persistência, valorizando múltiplas perspectivas e ontologias. Este estudo faz uma comparação entre três conjuntos cerâmicos e interpreta a relação peculiar entre Tupiniquim e portugueses como aliados e parceiros no processo colonial de São Paulo. As mulheres tupiniquim se apropriaram e transformaram o "outro português" e sua tecnologia em uma das materialidades coloniais - a cerâmica paulista. Tal fato não significou perda cultural, mas sim persistência de práticas por cinco séculos.
\end{abstract}

Palavras-chave: Estudos pós-coloniais; Tupi; História de longa duração; Práticas cerâmicas; Povos indígenas; Gênero.

\author{
PAULISTAWARE: FIVE CENTURIES \\ OF THE PERSISTENCE OF \\ TUPINIQUIM PRACTICES IN SÃO \\ PAULO AND PARANÁ, BRAZIL
}

\section{Abstract}

The Archeology of Colonialism in Brazil of the last decade is thought to decolonize the field. It has begun to reveal and build stories of persistence, valuing multiple perspectives, and ontologies. This study compares three types of ceramics and interprets the relationship between Tupiniquim and Portuguese as allies and partners in the colonial process of Sao Paulo. The women appropriated and transformed the "Portuguese other" and their technology into one of the Tupiniquim colonial materialities - the paulistaware, which signifies not a cultural loss, but cultural persistence of practices for five centuries.

Key words: Postcolonial studies; Tupi peoples; Long duration History; Ceramic practices; Indigenous peoples; Gender. 
LA ALFARERÍA PAULISTA: CINCO

SIGLOS DE PERSISTENCIA DE

PRACTICAS TUPINIQUIM EN SÃO

PAULO Y PARANÁ, BRASIL

\section{Resumen}

La arqueología del colonialismo en Brasil ha sido concebida desde la última década como el intento descolonizador de su campo de investigación. Ha buscado percibir y construir historias de persistencia, valorando perspectivas y ontologías múltiples. Esta investigación hace una comparación entre tres conjuntos alfareros e interpreta la relación peculiar entre los Tupiniquim y los portugueses cómo aliados y compañeros en el proceso colonial de São Paulo. Las mujeres Tupiniquim apropiaron y transformaron el "otro portugués" y su tecnología en una de las materialidades coloniales: la cerámica paulista. Este hecho no significó una pérdida cultural, y si la persistencia de prácticas por cinco siglos.

Palabras clave: Estudios poscoloniales; Tupi; Historia de larga duración; Prácticas alfareras; Pueblos indígenas; Género. 